\title{
THE NUCLEAR CONFIGURATION AND CORTICAL CONNECTIONS OF THE HUMAN THALAMUS
}

\author{
JACK G. SHEPS \\ The Neuropsychiatrio Institute, University of Miohigan, Ann Arbor ${ }^{1}$ \\ TWENTY Plates (TWENTY-FOUR FIGURES)
}

\section{INTRODUCTION}

The present paper is part of a series of studies on the human thalamus. The plan is to use suitable pathological material as a substitute for the experimental data available for subhuman studies, and to check such findings against normal preparations. It is hoped to provide thus a better understanding of the more detailed connections of the normal human thalamus and to see in what ways these connections and their functionally associated groups are comparable to, and in what ways they differ from, those of closely related forms. The object, then, is a better understanding of the normally functioning human thalamus. As a useful basis for this work, a preliminary résumé of the major nuclear groups of the human thalamus is given. Then the first of the series of cases pertinent to the problem under consideration will be presented.

The structure and the connections of the mammalian dorsal thalamus have been studied extensively. There have been relatively few studies of the human thalamus since the beginning of the century; then the work of von Monakow (1895) formed the basis for an understanding of this region. The usual descriptions and illustrations of the human thalamus in atlases and modern textbooks are still, for the most part, based on his conceptions. The older workers did not have the advantages of modern technical methods, and their descriptions were very gross, depending on myelin stains or on large nuclear districts stained with carmine. Most modern textbooks in their mention of recent advances in the form and function of the thalamus use illustrations and references from current work on primates. There are some exceptions to this ; for example, Mettler ('42) and Riley ('43) have figured certain of the nuclear groups in the human thalamus.

\footnotetext{
${ }^{1}$ This paper was aided by a grant of the Board of Governors of the Horace H. Rackham School of Graduate Studies of the University of Michigan and to this Board grateful acknowledgment is made. The author also wishes to express his sincere thanks to Dr. K. Lowenberg for suggesting this problem and for his help and encouragement throughout and to Dr. Elizabeth Grosby for many invaluable suggestions.
} 
In the last century, Burdach (1819) divided the thalamus into the four classical divisions: tuberculum anterior, outer nucleus, inner nucleus and pulvinar. Later Meynert (1872) subdivided the outer nucleus into ventral and dorsal divisions. Ramón 'y Cajal ('11) agreed with this description of the thalamus, but in the detailed accounts of the various thalamic divisions his references to man are few, and his illustrations are based almost solely on subhuman material. From anatomical studies of normal and pathological subhuman and human thalami, von Monakow (1895) recognized in the ventral nucleus an anterior (rostral) and a posterior (caudal) portion and further subdivided the latter into medial, lateral and posterior nuclei. Déjerine ('01) drew attention to myeloarchitectural differences between the dorsal and ventral divisions of the "external" nucleus and pointed out some cytoarchitectural differences in various portions of the ventral nucleus, but he did not subdivide the thalamus further. Malone ('10) described the cell structure of the human thalamus, but since he designated his nuclei purely on the basis of the types of cells, his divisions are very different from those of most workers. Foix and Nicolesco ('25) and Grünthal ('34) have described the human thalamus. Since extensive bibliographies accompany most of the references quoted, a complete review of the literature is not given here; only the more detailed and complete studies are mentioned.

Studies of the cortical connections of the human thalamus have been carried on by von Bechterew (1887, 1894, '05, '06), von Monäkow (1895), Déjerine ('01), Sachs ('09), Wenderowic ('15), Fukuda ('19), Papez ('37), Le Gros Clark and W. R. Russell ('39), Le Gros Clark and D. S. Russell ('40), Papez, Bull and Stotler ('40) and C. and O. Vogt ('41). Déjerine presented the thalamic degenerations consequent to cortical destruction in a large series of cases; von Monakow studied several such cases and Fukuda reported cases of thalamic degeneration secondary to lesions in the frontal lobe. As has been pointed out, technical difficulties, particularly the absence of a good cell stain and the lack of knowledge of the finer structure of the human thalamus, hindered the studies of Déjerine, von Monakow and Fukada, and made the interpretation of their findings variable and difficult. The more recent contributions are discussed in greater detail in connection with the descriptions of the various nuclei.

Recent studies of the thalamus of higher primates and its connections have emphasized the need for similar detailed studies in man. Myelin sheath stains are only presumptive and do not give certain evidence of the intensity or extent of nuclear degeneration, and detailed interpretation of the thalamic degeneration must rely mainly on techniques which give cell stains. In Walker's ('38) comprehensive work on thala- 
mic degenerations, following cortical ablation in Macaca mulatta, cell stains were used exclusively.

No attempt has been made in this paper to cover completely the literature on human thalamus and only such papers dealing with the thalamus in other primates and in subprimates have been quoted which contained material particularly pertinent to the discussion at hand. Such omissions have been made to some extent in the interest of saving space but more particularly because the writer believes that the experimental literature and that dealing with detailed accounts of fiber connections in normal material, can best be considered when a large series of overlapping patho-anatomical cases and those involving circumscribed lesions, which he is endeavoring to collect, permit a more detailed account of specific connections within the human thalamus. Moreover, much of the literature on the subhuman nuclear pattern of the dorsal thalamus has already been reviewed in other papers. Certain fairly recent books present reviews of much of the literature on the diencephalon up to their publication. For example, the monograph by Poliak ('32) and the books by Ariëns Kappers, Huber and Crosby ('36) and Walker ('38) contain extensive bibliographies and discussions of the mammalian diencephalon. Among the many papers which might be consulted both for their content and for their references to some of the more recent literature, are the accounts of Le Gros Clark ('30, '32, '32a, '36, '37), Le Gros Clark and Boggon ('32, '33, '35), Le Gros Clark and Northfield ('37), Mettler ('35, '35a; '35b, '35c and elsewhere), Walker ('34, '35, '36, '37), Waller ('34) and Waller and Barris ('37), Bailey, Poliak and Walker ('35), Bodian ('39, '40, '42), Bucy and Klüver ('40), Bailey, Dusser de Barenne, Garl and McCulloch ('40); Spiegel, Miller and Oppenheimer ('40) and Papez ('37 and '44).

\section{MATERIALS AND METHODS}

Two normal human brains were used for the study. The celloidin blocks were eut in serial sections of $40 \mu$ thickness and stained by Nissl's method, with thionin as the dye. One series of sections was coronal, the other sagittal. The use of a magnifying glass with the large photomicrographs is suggested, in order to bring out greater detail than is apparent with the unaided eye.

Microscopic material was also prepared illustrating, in three cases, the thalamic degenerations in man. This human experimental material permits an analysis of certain thalamic connections.

DESCRIPTION OF NORMAL MATERIAL Anterior nuclear group

The anterodorsal, anteroventral and anteromedial nuclei, with the oral portions of the nuclei reticularis and ventralis anterior, form the most rostral part 
of the thalamus (fig. 1). This anterior group of nuclei is well delimited rostrally, but caudally its ventral bordor blends with the midline, medial and ventral nuclear groups.

Nucleus anterodorsalis (figs. 1 and 2). The anterodorsal nucleus is a thin layer of cells which caps the other two nuclei rostrally (fig. 9). It may be a distinct, broad gray band or a thin, indistinct cellular mass one or two cells wide and well demarcated by fibers. In some sections it is lacking.

It appears first in the anterior tubercle, just caudal and medial to the rostral pole of the anteroventral nucleus. Caudalward the parataenial nucleus intervenes between the anterodorsal nucleus and the dorsal surface of the thalamus. The anterodorsal nucleus first surrounds the ventromedial angle and extends about halfway up the medial border of the anteroventral nucleus but, as the anteromedial nucleus appears, the anterodorsal nucleus expands ventrally to cnelose its ventromedial corner. With the caudal increase in the anteromedial nucleus, the anterodorsal nucleus shifts dorsally, forming a straight, thin band of cells, medial to the middle third of the combined medial borders of the anteroventral and anteromedial nuclei. Caudally it is continuous with nucleus interanterodorsalis.

The cells are large, deeply staining, partly flask-shaped but mostly fusiform, and they are lined up with their long axes in the direction of the fibers.

Anteroventral nucleus (figs. 1, 2, and 3). The largest of the anterior group, the anteroventral nucleus, appears in the rostral portion of the anterior tubercle and extends to the massa intermedia. Rostrally it is circular, but caudally it assumes an oval or rhomboid outline. Except for a considerable intermingling of its cells with those of the anteromedial nucleus, it is surrounded by a clear fiber zone (fig. 2). The dorsomedial nucleus replaces the anteromedial nucleus farther caudalward. The anteroventral nucleus is separated laterally by the internal medullary lamina from nucleus ventralis anterior rostrally and nucleus ventralis lateralis caudally. In its rostral half, it forms the medial part of the dorsal border of the thalamus (fig. 1), but approximately at its midpoint, nucleus lateralis dorsalis appears as a thin strip of cells between it and the dorsal border of the thalamus. Nucleus lateralis dorsalis rapidly increases in size caudally and enlarges ventrally, replacing nucleus anteroventralis, which is reduced first to a thin half-moon shape (fig. 3) and finally replaced entirely.

Nucleus anteromedialis (figs. 1 and 2). Nucleus anteromedialis is ventral to about the middle half of nucleus anteroventralis. Rostrally the anteromedial nucleus is surrounded by a distinct fibrous layer, except rostrodorsally, where it grades over into the anteroventral nucleus shown but not labelled (fig. 1). Caudally it blends with its surroundings and is defined mostly on the basis of cell type. Laterally it is bounded throughout by the internal medullary lamina. In its rostral portion it is bounded ventrally by the medial part of the internal medul. lary lamina, except where the ventral portion of the anterodorsal nucleus intervenes. Farther candalward the anteromedial nucleus expands ventrally and blends with the medial portion of nucleus ventralis anterior, the nuclei being differentiated chiefly by differences in cytoarchitecture. The ventral part of the medial border of the anteromedial nucleus is separated here from the ventricular wall by nucleus anterior paraventricularis, nucleus parataenialis and nucleus reuniens (fig. 2). The mammillo-thalamic fibers stream into the ventrolateral portion of the nucleus. 
In its caudal third the nucleus is gradually replaced by the dorsomedial nucleus, pars magnocellularis of which first appears as a small indentation of cells of larger size and pinkish tinge in the dorsal half of the medial border (fig. 17) and expands rapidly caudally, replacing the anteromedial nucleus. $A$ few sections caudal to the appearance of the dorsomedial nucleus, almost the whole ventral two-thirds of the anteromedial nucleus has been replaced dorsally by the dorsomedial nucleus and ventrally (from medial to lateral) by the nucleus submedius, nucleus paracentralis and nucleus centralis lateralis. The transition between the anteromedial nucleus and the latter three nuclei is indistinct and gradual. The caudal part of the anteromedial nucleus also loses the fibrous border separating it from the midline nuclei and their cells intermingle. The dorsal third of nucleus anteromedialis persists farthest caudally, but it is finally replaced by the dorsomedial nucleus.

The anteroventral and anteromedial nuclei are composed of large, mostly globular neurons with many thick, branching processes. Some small, poorly defined tigroid bodies are distributed throughout the moderately well staining cytoplasm, and most cells contain a mass of dark staining tigroid substance at the base.

In man, the anterior group of nuclei resembles that described by Crouch ('34) and Walker ('38) in Macaca mulatta. In Cercopithecus, Friedemann ('12) and Vogt ('09) both described only a main anterior nucleus and a thin accessory anterior nucleus, situated dorsally. Grünthal ('34), Foix and Nicolesco ('25), as well as eertain older authors, mentioned only one nuclear mass in the anterior group in man.

\section{Lateral nuclear group}

The nuclear mass caudal to the front end of the nucleus reticularis and rostral to the pulvinar between the external and internal medullary laminae is divided into a ventral and a lateral nuclear group. Rostrally it consists of the ventral nuclear group and the small nucleus lateralis dorsalis, but caudally the ventral nucleus forms only its ventral half.

Nucleus ventralis anterior (figs. 1 and 2). Nucleus ventralis anterior is surrounded by a well-marked fibrous capsule, except caudally, where it gradually merges into nuclcus ventralis lateralis. It is distinguished by islets of large, deeply-staining cells separated by coarse bundles of fibers.

Nucleus reticularis surrounds nucleus ventralis anterior, except medially. The fibers of the periventricular system and the inferior thalamic peduncle run directly medial to the ventromedial corner of the oral portion of nucleus ventralis anterior to reach the anterior nuclei. Nucleus ventralis anterior enlarges caudally and shifts ventrally and medially to form a ventral relationship, first to nucleus anteroventralis and then to the anteromedial nucleus. In this position its ventromedial corner is separated from the ventricular surface rostrally by nucleus anterior paraventricularis and caudally by nucleus reuniens. The mammillothalamic bundle traverses nucleus ventralis anterior lateral to the inferior thalamic peduncle (fig. 2).

At the level of a plane through the caudal border of the anterior commissure, a gradual replacement of this nucleus by nucleus ventralis lateralis occurs. There is a gradual disappearance of the islands of cells and, in general, a change to more 
compact, more evenly distributed and more deeply staining cells, separated by finer, laterodorsally running fibers. This change occurs first in the medial and dorsal portions (fig. 2), then latsrally and ventrally. In the zone of transition the cell types of both nuclei intermingle.

The cells of this nucleus are slightly smaller than those of the reticular nucleus. They are ovoid or globular, with a tendency to pyramidization, and possess many branching processes. The cell body stains faintly, and in it there are usually a few small, indefinite, more deeply staining Nissl granules. Occasionally there are clusters of coarse, deep-staining granules, situated perinuclearly at the base of the cell.

Nucleus ventralis lateralis (figs, 3 and 4). This nucleus lies between nucleus ventralis anterior and the three nuclei ventrales posteriores (intermedius, lateralis and medialis) and rostrally nucleus reticularis is dorsal. The internal medullary lamina forms a broad fibrous band dorsally but becomes thin and indistinct ventrally, where it separates the ventromedial corner of nucleus ventralis lateralis from the medial and midline group of nuclei (fig. 3 ).

At rostral levels medial relations of the nucleus (fig. 3 ) dorsoventrally, are: nueleus lateralis dorsalis, nucleus anteroventralis, nucleus anteromedialis, nucleus dorsomedialis, nucleus submedius and nucleus reuniens. The medial tip is separated from the main portion of the nucleus by the broad mammillo-thalamic tract. Caudally, as massa intermedia is approached, nucleus paracentralis and nucleus centralis lateralis appear medial to nucleus ventrolateralis. The anterior group of nuclei disappears, and the medial relationships, dorsoventrally, are nuclei lateralis dorsalis, dorsomedialis, paracentralis, submedius and reuniens. The periventricular fibers course through and break up the compactness of the ventromedial tip of nucleus ventralis lateralis and form a thin, fibrous layer separating it from the midline and medial nuclei. Farther caudalward the fibers do not enter the nucleus but dwindle to form a very thin capsule. At the oral border of centrum medianum, nucleus ventralis posteromedialis appears and replaces the medial and ventral portions of nucleus ventralis lateralis. In the dorsomedial corner of the caudal third of nucleus ventralis lateralis, nucleus lateralis posterior appears and soon enlarges caudally, to replace the dorsal portion of the nucleus. The mammillo-thalamic bundle lies entirely ventral to the ventromedial angle of the caudal portion of nucleus ventralis lateralis, and nucleus ventralis posterior intermedius intervenes between nucleus lateralis posterior and nucleus ventralis lateralis, at the expense of the latter nucleus, which is ultimately replaced by nucleus ventralis posterolateralis.

Pars ventralis of nucleus ventralis lateralis, situated in the ventrolateral portion of the nuclear complex, forms a distinct subnucleus for the whole extent of this complex. It is well demareated by fibers (fig. 3 ). Nucleus ventralis lateralis is composed of large and small cells. The large cells are polygonal and have many broad processes. The cytoplasm stains deeply, and there are a few coarse, ill-defined Nissl bodies near the periphery. The small neurons are flask-shaped, rounded or fusiform, with many branching processes. The nucleus appears too large for the cell body, and the cytoplasm is lighter than that of the large cells. Distribution of these cells varies. In the medial and dorsal parts the large neurons are fewer and somewhat smaller. The lateral and ventral parts (pars ventralis) of nucleus ventralis lateralis are less compact, the cells being separated by fiber 
bundles. The cells of the caudal end of the ventrolateral part of the nucleus show an increase in size, and the proportion of large cells to small also increases.

Nucleus ventralis posterior medialis (figs. 4, 5 nd 6 ). Nucleus ventralis posterior medialis extends from the rostral tip of centrum medianum to the point of the greatest development of the habenula. Its oral part is surrounded by nucleus ventralis lateralis, except medially. It forms a cap around the lateral and ventral borders, and the lateral part of the dorsal border, of centrum medianum (fig. 4). As centrum medianum enlarges caudally, nucleus ventralis posterior medialis shifts laterally and borders only its lateral and ventral edges. Caudally nucleus lateralis posterior intervenes between nucleus ventralis posterior medialis and the lateral border of centrum medianum. In the caudal portion of the thalamus, the medial division of the pulvinar replaces nucleus lateralis posterior (fig. 5).

Rostrally nucleus ventralis posterior medialis is half-moon shaped, with a bulbous enlargement at the lateral tip and a somewhat narrowed medial tip (fig. 4). As nucleus lateralis posterior expands caudally, it pushes the lateral tip of nucleus ventralis posterior medialis ventrolaterally, so that the latter lies horizontally (fig. 6). Caudally the nucleus shrinks, and the medial portion disappears first, a few sections rostral to its caudal pole. In the most oral portion it is lateral to nucleus centralis lateralis and centrum medianum. Nucleus paracentralis is dorsal, and nucleus centralis medialis is dorsal and medial to the medial tip of nucleus ventralis posterior medialis. Caudally the nuclei centralis lateralis, paracentralis and centralis medialis disappear, the latter two being replaced by the periventricular gray. Dorsal to the medial portion is centrum medianum, and more caudally, in a medial position, is nucleus parafascicularis (fig. 6).

Nucleus lateralis posterior first lies dorsal to nucleus ventralis posterior medialis, but as it is traced caudalward, it enlarges and is medial and lateral to the lateral tip of nucleus ventralis posterior medialis to the level of the habenula, where the medial division of the pulvinar takes over these relationships (fig. 5). In the region of its greatest expansion, nucleus ventralis posterior lateralis forms the major dorsal relationship of nueleus ventralis posterior medialis for a short distance rostrocaudally, before the former is replaced by nucleus lateralis posterior.

The lateral relationships of nucleus ventralis posterior medialis, rostrocaudally, are nucleus ventralis lateralis and nucleus ventralis posterolateralis. The ventral relationships, rostrocaudally, are the medial tip of nucleus ventralis lateralis, the medial tip of nucleus ventralis posterior lateralis, and finally the medial part of the pulvinar.

The nucleus is composed of two types of cells : large ones with deeply staining cytoplasm, very large, well-defined, dark staining tigroid bodies and stout, branching processes, and smaller, medium-sized, paler staining cells with indistinct Nissl bodies and many fine processes. Orally it is quite cellular, with few large cells, but caudally the proportion and size of the large cells increase, although they are not quite so large as those of nucleus ventralis posterior lateralis. The nucleus is bounded by a thin fibrous capsule.

Nucleus ventralis posterior lateralis (figs. 5 and 6). The oral part of nucleus ventralis posterior lateralis occupies the ventrolateral portion of the lateral nuclear mass. Caudally the nucleus shrinks, and first its medial and then its dorsal portion is replaced by nucleus lateralis posterior. The pulvinar finally 
replaces it entirely. In cell stains it is distinguished from nucleus ventralis lateralis mainly by the absence of a pars ventralis and by the larger size of its cells.

The oral portion is bounded medially by nucleus ventralis posterior medialis; the medial tip by the periventricular gray. Rostrodorsally lies nucleus lateralis posterior, and rostrocaudally the pulvinar. Nucleus ventralis posterior lateralis is crescent-shaped, much like nucleus ventralis posterior medialis, but with a much expanded dorsal extremity, and it is roughly twice the size of the latter. Its medial aspect in the caudal portion is mostly fibrous (fig. 5).

The cells are the same as those of nucleus ventralis posteromedialis. Rostrally the nucleus is quite cell-poor, containing relatively few small neurons. Caudally it becomes more cellular; the large cells increase in size to become the largest in the thalamus, and the ratio of small to large cells increases.

Nucleus ventralis posterior intermedius. Nucleus ventralis posterior intermedius consists of large, deeply staining cells arranged in vertical rows. It is quite small - about five cells in dorsoventral extent — stretching in a slightly oblique horizontal plane, dorsoventrally and lateromedially, from the external medullary lamina to the dorsolateral tip of nueleus ventralis posterior medialis. It runs for a short distance between nucleus lateralis posterior dorsally and the caudal extremity of nucleus ventalis lateralis ventrally, until it is replaced by meleus ventralis posterior lateralis. Difficult to distinguish, it is recogn.zed by the arrangement and more deeply-staining, slightly larger appearance of its cells. Its exact limits are probably inconstant, as it varies considerably in extent on the two sides.

Nucleus lateralis dorsalis (figs. 3 and 4) and nucleus lateralis posterior (figs. 4 and 8). Nucleus lateralis dorsalis extends from the level of the oral, largecelled portion of the dorsomedial nucleus to the habenula. First it appears as a thin layer of cells between the anteroventral nucleus and the dorsal border of the thalamus. Medial to nucleus ventralis lateralis it is surrounded on all sides by a branch of the internal medullary lamina, which splits to enclose it. It. is rather inconstant rostrally, but eaudally it increases rapidly in size and becomes cigar-shaped, with its long axis roughly parallel to the dorsal surface of the thalamus (fig. 3). It replaces the anteroventral nucleus, the medial part of its ventral border lying immediately dorsal to the dorsomedial nucleus. The lateral part of its ventral border is medial to nucleus ventralis lateralis, which is replaced caudally by nucleus lateralis posterior.

In its expansion, nucleus lateralis dorsalis increases ventromedially. Orally the medial tip is in relation to nucleus interanterodorsalis, and caudally to nucleus parataenialis (fig. 4). The nucleus is somewhat smaller in its caudal third, which merges with the medial portion of the pulvinar.

Nucleus lateralis posterior (fig. 4) extends from a plane through the middle of massa intermedia to the level of the habenula, where it is continuous with the pulvinar. It is very compact, and small bundles of fine, transverse myelinated fibers run through it. It is not well encapsulated and is recognized on the basis of its distinctive cytoarchitecture.

Nucleus lateralis posterior is small as it first appears, replacing the dorsomedial corner of nucleus ventralis lateralis, but more caudally it occupies the entire dorsal half of the lateral nuclear mass. Because of its own expansion together with 
that of the lateral nuclear mass, it forms a cap around the dorsolateral portion of the dorsomedial nucleus.

At a more caudal level, centrum medianum and nucleus ventralis posterior medialis are ventromedial, and nucleus ventralis lateralis is ventrolateral to nucleus lateralis posterior. As nucleus ventralis posterior intermedius appears, it intervenes between nucleus lateralis posterior dorsally and nucleus ventralis lateralis ventrally. Finally nucleus ventralis posterior lateralis lies ventrolateral to nucleus lateralis posterior.

The lateral nuclei are compact and are made up of globular, fusiform and a few pyramidal cells. The size of the cells is not uniform, but in general the neurons are small with many processes. The cell nucleus is somewhat large in relation to the cell body, which stains fairly deeply and occasionally contains a few coarse tigroid bodies arranged perinuclearly. The cells of nucleus lateralis posterior are a little larger and less compactly arranged than in other portions of the lateral group.

Nucleus reticularis (figs. 1, 2, 4, 5, 6 and 8). Nucleus reticularis is a thin, frequently broken line of cells, forming the most oral part of the thalamus and lying rostral, dorsolateral, lateral and ventral to the lateral nuclear mass. Its oral and ventral extent are best seen in sagittal sections (fig. 8). For the most part it is separated from the rest of the thalamus by a thick, fibrous border (external medullary lamina and dorsal border of the thalamus), but in its oral portion the lateroventral and ventral parts are bounded by a thin, indistinct fibrous layer.

The ventral portion of nucleus reticularis is continuous with zona incerta. The oral pole of nucleus ventralis anterior replaces the medial and central portions of nucleus reticularis, and the latter remains as a thin line of cells dorsal, lateral and ventral to the lateral nuclear mass. Caudal to zona incerta it consists only of a dorsal and a lateral portion. It lies lateral to the pulvinar and lateral geniculate body at its caudal limit, which is at the level of the caudal pole of the lateral geniculate body.

The cells are large, polymorphous or pyramidal with many stout processes, and they contain large, coarse, deeply staining tigroid bodies in the lightly staining cytoplasm. The cells occur in little groups, separated by thick fibrous bundles, and their long axes are arranged in the direction of the fibers.

Meynert (1872) first subdivided the external thalamic nucleus of his account into dorsal and ventral nuclei. Déjerine ('01) mentioned the myeloarchitectura] differences between the ventral and dorsal portions of the external nucleus. Von Monakow (1895) also acknowledged the division of the lateral nucleus into a dorsal and a ventral portion, but admitted that his interpretation, based on cytoarchitectonic studies, might be influenced by subjective factors. Foix and Nicolesco ('25) did not subdivide the external nuclear mass, and Grünthal ('34) definitely stated that he did not consider the division justified on the basis of cytoarchitecture. Jacob ('11) included all nuclei which receive sensory impulses, both from the optic tract and from the lemnisci, in his "Basothalamus." Nuclei parafascicularis, centralis medialis, centrum medianum, limitans, ventralis lateralis, the oral part of the pulvinar and the nucleus ventralis posterior medialis are grouped together. 
This division has been recognized in the rat by Gurdjian ('27), in carnivores by Rioch ('29), in Cercopithecus by Friedemann ('12) and Vogt ('09) and in Macaca mulatta by Crouch ('34) and Walker ('38). It appears inconsistent, therefore, that it should not be present in man. Absence of large neurons and compactness of the nuclei seem definitely to distinguish the lateral from the ventral nuclei. The lateral nuclei described in the present account are homologous with those of Macaca mulatta, as described by Walker. Friedemann and C. Vogt subdivided them somewhat further and traced them more rostrally, but in general their descriptions agree with the present account.

Von Monakow first subdivided the ventral nucleus. The oral portion, extending from the rostral tip of the thalamus to the level of the subthalamic body, he termed the anterior ventral nucleus. The posterior ventral group, which he divided into a medial, a lateral and a posterior nucleus, extended to the pulvinar. This coincides with the nucleus ventralis posterior, with its two subdivisions, as described here. The ventral posterior nucleus of von Monakow's account appears to be the inferior division of the pulvinar of this account. Déjerine mentioned the fact that the anterior segment of the external nucleus is composed of small groups of neurons arranged in clusters. He also noted that in the posterior portion of the external nucleus, especially near centrum medianum, the cells of the medial portion (corresponding to nucleus ventralis posterior medialis) are somewhat smaller and more compact than those at the same level laterally. Near the external medullary lamina, large neurons - twice as large as the others - occur in small groups.

Foix and Nicolesco ('25) mention two subdivisions of the lateral nuclear mass, the posterior inferior external nucleus and the semilunar nucleus. Of these, the posterior inferior external nucleus, which, in topographical relations, coincides with nucleus ventralis posterior lateralis of the present author, is described as composed of two types of cells. One type consists of large, dark staining neurons, the largest in the thalamus, arranged in groups in a matrix of smaller, pale staining cells. They also mention collections of relatively large cells in the ventral part of the external nucleus at the entrance of the rubro-thalamic tract. This area probably coincides with pars ventralis of nucleus ventralis lateralis. They describe the semilunar nucleus as having the same cytological characteristics as the external part of nucleus posterior inferior but with somewhat smaller cells.

As already stated, Grünthal ('34) did not differentiate between the lateral and the ventral nuclei, and therefore his results do not entirely agree with those described in the present account. He appears to have designated pars ventralis of nucleus ventralis lateralis as $l . p . r .4$, and nucleus ventralis posterior lateralis as l.p.r.8. L.p.r.8 is the only region in which he distinguished large and small neurons. He identified the caudal portion of nucleus ventralis posterior medialis as l.p.r.7 and appears to have indicated the nucleus lateralis dorsalis as d.p.a. Nucleus lateralis posterior is indicated by the eaudal portion of his l.p.r.1, and the dorsal portion of l.p.r.6. Grünthal did not recognize the reticular nucleus.

The ventral nuclei described in the present account are homologous with those seen by Walker ('38) in Macaca mulatta. Friedemann ('12) and Vogt ('09) did not differentiate nucleus ventralis anterior from the remainder of the lateral and ventral nuclei, but in general their nuclei agree with the above description. Friedemann described large, dark staining cells and smaller, lighter staining ones 
in the ventral nucleus, with almost the same variations in cytoarchitecture as described above.

\section{Midline nuclei}

Nucleus paraventricularis anterior (figs. 2,3 and 4). Nucleus paraventricularis anterior lies in the periventricular gray and appears to be a condensation of its cells. It extends from the rostral end of stria medullaris thalami to the habenula. Rostrally its shape in cross section in a vertical oval, but caudally it becomes square, then rectangular, and finally it narrows to a thin, vertical strip of cells.

The rostral extremity lies between nucleus parataenialis and the column of the fornix. Nucleus parataenialis is between it, and the anteromedial nucleus. Lateroventral are the fibers of the periventricular system and the inferior thalamic peduncle. A short distance caudalwards, nucleus reuniens appears, intervening between the columns of the fornix and nucleus paraventricularis anterior. In places a thin fiber layer separates the two nuclei, but usually they are not sharply demarcated. Lateral are the nuclei ventralis anterior and anteromedialis (fig. 2) and finally nucleus dorsomedialis (fig. 3). Here the anterior paraventricular nucleus becomes a thin, vertical strip of cells and shifts dorsally (fig. 4).

The rostral tip of the rhomboid nucleus intervenes between nucleus paraventricularis anterior and nucleus dorsomedialis. The rostral pole of the lateral division of nucleus centralis medialis blends intimately with nucleus reuniens. As nucleus rhomboidalis develops caudally, it replaces the ventral portion of nucleus paraventricularis anterior, reducing it to one of two thin, vertical lines of cells. Nucleus paraventricularis anterior blends with the dorsal and medial portions of nucleus rhomboidalis, and a definite boundary cannot be recognized (fig. 3).

With the caudal shrinking of nucleus rhomboidalis, nucleus paraventricularis anterior increases in size and expands ventrally. Where the large-celled portion of the dorsomedial nucleus occurs, the boundary between the two is very indefinite (fig. 4). Caudal to nucleus centralis medialis, nucleus paraventricularis anterior becomes an indefinite condensation of cells in the periventricular gray. It shrinks, becomes inconstant and is shifted ventrally by the increase in size of stria medullaris thalami. In its most caudal part, it is medial to the medial tip of the dorsomedial nucleus.

Nucleus paraventricularis anterior is composed of large, pear-shaped cells intermingled with occasional fusiform and oval forms having many processes. The cytoplasm stains moderately well, and there are usually a few small, ill-defined tigroid granules.

Nucleus paraventrioularis posterior (fig. 6). This is a thin, vertical strip of cells, distinguished from the rest of the periventricular gray in which it lies by its greater compactness and larger, more deeply-staining cells. Caudally it fades into the periventricular gray of the pretectum. It appears just caudal to the rostral extremity of the habenula. At its rostral end the medial border of centrum medianum lies lateral to it but is soon replaced by nucleus parafascicularis. Ventrally and dorsally the posterior paraventricular nucleus fades into the surrounding periventricular gray.

The cells are small and spherical, fusiform or flask-shaped with many processes. The cell body stains lightly but contains many large, deeply-staining Nissl bodies, arranged perinuclearly. 
Nucleus reuniens (figs, 2 and 3 ). This is the most ventral of the midline nuclei, extending from levels through the caudal part of the anterior tubercle to the middle of massa intermedia and lying directly lateral to the ventricular wall. The oral portion lies dorsal to the column of the fornix. Farther caudalward, nucleus reuniens is dorsal to the hypothalamic nucleus paraventricularis, and there is no sharp line of demarcation between them. The external medullary lamina separates nucleus reuniens from the fornix but becomes very indistinct caudally.

In its rostral extent nucleus reuniens is ventral to nucleus paraventricularis anterior (fig. 2). Lateral to it are the fibers of the periventricular system and the inferior thalamic peduncle, separating it from nucleus ventralis anterior. Rostrally the nucleus is rectangular with the longest edge horizontal. It enlarges caudally, and, as the fibers of the periventricular system shift laterally, lies directly medial to nucleus ventralis lateralis, with which gray its cells intermingle. With the enlargement of nucleus reuniens, the lateral portion of its dorsal border comes into relation with the anteromedial nucleus. A short distance caudally the rostral portion of the lateral division of nucleus centralis medialis intervenes, close to the midline, between nucleus paraventricularis anterior and nucleus reuniens. Nucleus submedius, the caudal pole of nucleus anteromedialis and the ventromedial portion of nucleus ventralis lateralis are situated lateral and dorsolateral to nucleus reuniens in this position. Their cells intermingle, so that recognition of their borders must be, to a large extent, subjective. However, because of the rapid caudal growth of nucleus centralis medialis and the interposition of nucleus submedius between nucleus paraventricularis anterior and nucleus reuniens, the latter comes to occupy a position ventral to massa intermedia. The ventral border of the lateral division of nucleus centralis medialis is dorsomedial, and nucleus submedius is dorsal (fig. 3). Caudally nucleus reuniens grows smaller, encroached on dorsally by nucleus submedius, laterally by nucleus ventralis and ventrally by nucleus paraventricularis of the hypothalamus, until it finally disappears, giving way to a thin, midline strip of periventricular gray.

Nucleus reuniens is fairly compact and consists of small, globular, well-staining cells. Along its dorsal border to a varying extent, sometimes medial, sometimes lateral and sometimes invading the dorsolateral portion of the nucleus, are larger, more pyramidal, more deeply-staining neurons, often serving to identify and delineate the nucleus (fig. 3 ).

Nucleus rhomboidalis ( $f i g .3$ ). This is a triangular nucleus extending from a short distance caudal to the rostral portion of the lateral division of nucleus centralis medialis to a plane just caudal to massa intermedia. Orally it starts as a thin, vertical strip of cells, interposed between the dorsomedial nucleus and nucleus paraventricularis anterior. The rostral pole of nucleus submedius is ventral. Nucleus rhomboidalis increases rapidly in size caudally and forms a compact, small-celled nucleus. It remains situated in, and indents the ventromedial corner of, the dorsomedial nucleus through most of its extent. There is no fibrous border, and considerable intermingling of the cells of the two nuclei takes place, especially in the portion of the rhomboid nucleus.

As nucleus rhomboidalis expands medially towards the ventricular wall, nucleus paraventricularis anterior shifts dorsalward. Ventrally it remains in re- 
lation to the expanded nucleus submedius, except periventricularly, where the thin strip of the oral portion of the lateral division of nucleus centralis medialis lies. In this position nucleus rhomboidalis has a varying triangular or rhomboid shape. In places the dorsal portion of the nucleus may form two thin strips with periventricular gray between them. It is well demarcated ventrally throughout by the medial portion of the internal medullary lamina.

The caudalward expansion of the lateral portion of nucleus centralis medialis causes its dorsolateral tip to intervene between the ventral border of nucleus rhomboidalis and nucleus submedius. For a short distance the ventrolateral corner of nucleus rhomboidalis is in relation with the fibers of the periventricular system and the medial tip of the rostral pole of the paracentral nucleus (fig. 3), but with continued expansion of the lateral division of nucleus centralis medialis, the paracentral nucleus moves lateralward. The dorsal border of the lateral division of nucleus centralis medialis is now the sole ventral relationship of nucleus rhomboidalis.

In its rostral portion the nucleus is dense and compact, with small, lightlystaining granular cells, but its caudal portion is a thin, vertical band of cells in the caudal half of massa intermedia. It is less compact, and the cells appear to be lined up by vertically running fibers. The nucleus fades indistinctly into the periventricular gray. Nucleus rhomboidalis has a small, thin, but definite commissural portion, occurring in the rostral third of massa intermedia (fig. 3)

Nucleus parataenialis (figs. 2,3 and 4). Nucleus parataenialis extends along the whole course of stria medullaris thalami forming all but its medial boundary. Lateral to the nucleus is the anteromedial nucleus, except where the inconstant anterodorsal nucleus intervenes. The dorsal and ventral tips of nucleus parataenialis lie periventricularly.

Rostrally nucleus paraventricularis anterior is medial to the ventral tip of nucleus parataenialis, but caudally it lies directly ventral (fig. 2). The cells of these nuelei intermingle, and their borders are made out, somewhat subjectively, on the basis of cell type and arrangement. As nucleus dorsomedialis replaces the anteromedial nucleus it lies lateral to nucleus parataenialis, which expands somewhat caudally and reaches its greatest size at the level of the oral border of massa intermedia, where it forms a broad band of cells (fig. 3 ). As the anterodorsal nucleus fades out caudally, nucleus interanterodorsalis lies between it and nucleus lateralis dorsalis. The parataenial nucleus gradually shrinks, most markedly in the ventral half, which is finally reduced to a few scattered cells lying along the lateral and ventral borders of stria medullaris thalami. With the disappearance of nucleus interanterodorsalis, nucleus parataenialis lies medial and ventral to nucleus lateralis dorsalis (fig. 4).

The cells of the nuclear mass are polygonal, medium-sized and deeply staining with a large nucleus, the chromatin of which is arranged peripherally. They are larger and less dense than those of nucleus paraventricularis anterior.

Nucleus centralis medialis (figs. 3 and 4). Nucleus centralis medialis is the largest of the midline group of nuclei. With the commissural portion of nucleus rhomboidalis it forms massa intermedia. At its point of greatest enlargement it is shaped like a butterfly - divided into a midportion, or body, and two lateral divisions (fig. 3). The midportion constitutes most of massa intermedia, but the lateral portions extend in front of and behind the massa. Rostrally the lateral 
portions blend indefinitely with the ventral part of nucleus paraventricularis anterior at the level of the oral pole of nucleus submedius. Caudally they fade into the periventricular gray a short distance rostral to the habenula. The commissural portion is much smaller, extending from a plane slightly caudal to the rostral pole of nucleus lateralis dorsalis to approximately the rostral pole of centrum medianum.

Nucleus centralis medialis is situated between the medial ends of the internal medullary laminae. With nucleus centralis lateralis and nucleus paracentralis, it forms a thin, continuous, bow-shaped strip of gray, running among the fibers of the internal medullary lamina and bounding the ventral and lateral edges of the dorsomedial nucleus (fig. 3). The cells of the midline nuclear group stain more deeply than do the other neurons in the thalamus, with the exception of those constituting the magnocellular part of the dorsomedial nucleus.

The oral portion of each lateral division of nucleus centralis medialis appears as a thin strip of cells close to the midline, between nucleus paraventricularis anterior and nucleus reuniens. It is distinguishable from adjacent nuclei by its relatively cell-poor character.

Caudally nucleus rhomboidalis intervenes between nucleus paraventricularis. anterior and nucleus centralis medialis. Nucleus submedius is lateral and nucleus reuniens ventral. As the lateral divisions of nucleus centralis medialis continue to expand caudally and join the midportion to form massa intermedia, they assume a butterfly-wing shape. Medially their midportions join and laterodorsally they enter into relationship with the medial wall of nucleus paracentralis.

Farther caudally nucleus centralis medialis continues to expand, and the medial portion becomes oval with its long axis vertical. It is separated from the lateral portions by clefts which may be very deep and in places almost sever the connections. However, continuity of the nucleus is preserved dorsally. With the continued caudal expansion of nucleus centralis medialis and the corresponding decrease of nucleus rhomboidalis, the ventromedial tips of the dorsomedial nuclei enter into relationship with the dorsal borders of the lateral divisions of nucleus centralis medialis (fig. 3 ).

Caudal to this point the midportion of nucleus centralis medialis diminishes rapidly and finally disappears. The lateral divisions shrink more elosely. They lie close to the midline and, caudal to nucleus reuniens, are bounded ventrally by the periventricular gray. The diminution of nucleus submedius and the expansion of nucleus ventralis lateralis give the latter first a lateral and then a ventrolateral relationship to nucleus centralis medialis (fig. 4). Caudal to nucleus rhomboidalis, nucleus centralis medialis (now a thin strip) is separated from nucleus paraventricularis anterior, which is inconstant here, by a varying breadth of periventricular gray. Nucleus centralis medialis gradually fades into the periventricular gray.

The cells of nucleus centralis medialis are fairly large, deeply-staining and arranged as though interspersed among fibers. They are flask-shaped, with a tendency to pyramidization, and of the same type as those of nucleus paracentralis and nucleus centralis lateralis. Except for its rostral pole the nucleus shows a quite dense arrangement of neurons. Rosettes of cells of the magnocellular part of the dorsomedial nucleus invade the caudolateral portion of nucleus ecntralis medialis (fig. 4). 
Nucleus interanterodorsalis (fig. 3). This nucleus is the caudal continuation of the anterodorsal nucleus. Its rostral pole is a thin strip of cells interposed between the ventricular wall and the ventral tip of the laterodorsal nucleus, dorsal to the parataenial nucleus. Lateral to it, dorsoventrally, are nucleus anteroventralis, nucleus anteromedialis and nucleus dorsomedialis.

Caudally, as the anteromedial nucleus is replaced by the dorsomedial nucleus, nucleus interanterodorsalis becomes spherical and is bounded laterally only by the dorsomedial nucleus. As nucleus lateralis dorsalis expands ventrally, it lies lateral to nucleus interanterodorsalis and finally replaces it completely at about the level of the rostral third of massa intermedia.

This nucleus is more compact than nucleus anterodorsalis, and the cells are smaller. They are mostly spherical with many branching processes, and their cytoplasm stains the same deep blue as does that of the cells of nucleus anterodorsalis. The cells are not arranged in the direction of the fibers.

Griseum periventriculare (figs. 1,2 and 3). The periventricular gray is a thin zone of small fusiform or goblet-shaped, faintly staining cells around the ventricle. In the rostral portion of the thalamus this structure is replaced by the midline group of nuclei, but in the caudal portion of the thalamus it is quite distinct. It is associated with fibers of the periventricular system.

The midline group in man, as indicated by the foregoing account, is strikingly similar to that described by Rioch in carnivores except for its marked reduction in size. This would appear to be in accord with the phylogenetic history of the human thalamus. Former students of human thalamus mention only a few of these midline nuclei or group them together as "central gray." Foix and Nicolesco ('25) discuss the midline nuclei under the term of "substance grise, juxtaventriculaíre." Grünthal's ('34) subdivision of midline nuclei does not homologize with that described for lower mammals. In Macaca mulatta, Walker ('38) describes the nucleus parataenialis and nuclei paraventriculares, anterior and posterior, and nupleus centralis medialis, and groups the remainder as "massa grisea centralis."' Crouch's description (Crouch, '34) was essentially the same as Walker's, and he noted the strange fact that in Tarsius (Le Gros Clark, '30) the best developed midline nuclei are ventral, whereas in Macaca mulatta the best defined nuclei are dorsal, between the anterior nuclear group and the parataenial nucleus.

It is apparent that the nuclei of the midline are better developed in the lower mammals than in the higher mammals and man. However, that there are differences in the degree of development of this group is indicated by the various studies. In the material available for this account there is certainly a greater development than has previously been reported for the midline group in man. Two factors may account for this. In the first place the neurons of the midline group of nuclei are small and have a relatively small cell body in relation to the size of the nucleus. In order that they may be recognized as neurons, they must be studied in very well-fixed material. With inadequate staining methods or in poorly fixed or poorly prepared material, their nuclei stain densely, without a definite nucleolus, and their cell bodies may not take the stain. They may then be confused with glia cells. These neurons do not vary greatly. Recognition of the various nuclei in the group is based on grouping and compactness of arrangement. In the higher primates, where the gray occupies a relatively large 
area, a very low magnification (between 15 and 25) should be used, so that a large area is visible, in order to distinguish the grosser differences. In the second place, as is usual with structures the functions of which have been largely taken over by other, newer nuclei, the midline group tends to be inconstant among members of the same species.

While this manuscript was in preparation, studies were carried out on human thalamic degenerations consequent to cortical destruction. Close study of three more human brains indicated that there was a great difference in the development of the midline group. In two brains (L.B. and G.P.) there were practically no neurons in the medial division of the nucleus centralis medialis; in one of these (G.P.), nucleus reuniens and nucleus rhomboidalis were also greatly reduced and difficult to recognize. These factors may serve to expain the apparently inconsistent finding of a better developed midline group in some human thalami than in the thalami of primates studied.

Variability of development of the midline group appears to be the rule among primates and extends to marked variability in different human thalami.

\section{Medial nuclei}

These comprise the nuclei lying within or medial to the internal medullary lamina. The major representatives are nucleus dorsomedialis and centrum medianum.

Nucleus submedius (medialis ventralis) (fig. 3 ). This nucleus is cigar-shaped and appears to be the caudal extension of the ventromedial corner of the anteromedial nucleus. It exends to the caudal limit of the massa intermedia. Because of its intimate relation with the most medial part of the ventral nuclei it is sometimes placed in the lateral group.

At the level of the oral pole of nucleus rhomboidalis, nucleus submedius is oval with its long axis in the direction of the internal medullary lamina. It is clearly differentiated by difference in cell type from the rostral pole of the dorsomedial nucleus, which is dorsolateral to it. Dorsomedial is the ventral border of nucleus rhomboidalis. Lying lateral is the mammillo-thalamic tract. A short distance caudally the paracentral nucleus appears dorsolaterally. Medial to nucleus submedius is the ventral tip of nucleus paraventricularis anterior and the oral portion of the lateral division of nucleus centralis medialis. Ventral is the ventromedial tip of nucleus ventralis lateralis.

Caudally nucleus submedius shifts medially, becomes circular and lies lateral to nucleus centralis medialis, between nucleus rhomboidalis dorsally and nucleus reuniens ventrally. The internal medullary lamina forms at these levels its immediate dorsal and medial boundary. Lateral is the medial portion of nucleus ventralis lateralis. The separation of nucleus submedius from nucleus reuniens and nucleus ventralis lateralis is indistinct. The fibers of the periventricular system form a thin fibrous layer between it and nucleus ventralis lateralis. $\mathrm{Nu}$ cleus submedius enlarges caudally, and with the diminution of nucleus rhomboidalis and the growth of the lateral division of nucleus centralis medialis, the dorsolateral tip of the latter gray intervenes between nucleus rhomboidalis and nucleus submedius. The periventricular fibers form a broader band than before, separating nucleus submedius from the paracentral nucleus. With the continued caudal enlargement of the lateral division of nucleus centralis medialis, its dor- 
sal portion intervenes also between the dorsomedial nucleus and nucleus submedius and forms the latter's sole dorsal relation. The increased size of nucleus submedius brings it close to the ventricular wall, immediately ventral to massa intermedia (fig. 3).

Caudally the fibers of the periventricular system disappear, and the medial tip of nucleus ventralis lateralis encroaches more and more upon nucleus submedius, finally replacing it entirely.

The cells of this nucleus are flask-shaped, medium-sized and deeply staining, with nuclei quite small in comparison to the size of the cell body. They are arranged more or less concentrically surrounding fiber layers.

Nucleus paracentralis (figs. 3 and 7 ). This nucleus consists of a group of cells lying within the internal medullary lamina, between nucleus centralis medialis and nucleus centralis lateralis. It appears to be the caudal continuation of the lateroventral part of the anteromedial nucleus. It ends at about the same level as does the caudal pole of nucleus centralis medialis.

It begins as cells intercalated among the fibers of the internal medullary lamina and in general has a triangular shape with the apex dorsal, wedged between nucleus submedius medially and nucleus ventralis lateralis laterally. The base lies along the ventrolateral aspect of the dorsomedial nucleus. Fibers of the periventricular system pass through the apex and medial part of the oral half of this nucleus (fig. 3 ).

Slightly caudalward, on account of the expansion of nucleus rhomboidalis and nucleus centralis medialis, it enters into relationship with these two nuclei. $\mathrm{Nu}$ cleus rhomboidalis is dorsomedial and the lateral portion of nucleus centralis medialis is medial. The nucleus paracentralis continues caudally in this relationship until it is pushed lateralward by the expansion of the lateral division of nucleus centralis medialis. Because of this and of the shrinking of nucleus rhomboidalis at the same level, the sole dorsal relation of nucleus paracentralis is the ventrolateral border of the dorsomedial nucleus (fig. 3). Nucleus paracentralis shrinks gradually to a thin strip of cells. Centrum medianum appears, interposed between it and nucleus centralis lateralis (fig. 4). As centrum medianum increases in size caudally, it replaces nucleus paracentralis.

The cells of the paracentral nucleus are large, deeply-staining and gobletshaped. They appear to be arranged in a definite order along the fibers of the internal medullary lamina. The nucleus is well demarcated from nucleus sub. medius and nucleus centralis medialis, but its cells mingle with those of the dorsomedial and ventrolateral nuclei.

Nucleus centralis lateralis (figs. 3 and 4). This nucleus is a crescent-shaped mass of cells scattered among the vertically running fibers of the lateral portion of the internal medullary lamina. The rostral pole appears to be a lateral extension of nucleus paracentralis. It is closely applied to the ventrolateral border of the caudal pole of nucleus anteromedialis, separated from the latter by a capsular fiber layer, but with some intermingling of cells.

Nucleus centralis lateralis forms a cap around the dorsal half of the dorsomedial nucleus, between the latter and nucleus ventralis lateralis. It has a thin and inconstant medial portion entirely ventral to the dorsomedial nucleus, which joins with the lateral tip of nucleus paracentralis. As nucleus lateralis posterior appears caudally and expands medially and ventrally, it pushes nucleus lateralis 
dorsalis medioventralward and lies dorsal and lateral to the dorsal portion of nucleus centralis lateralis (fig. 4). Nucleus ventralis posterior medialis replaces the medial portion of nucleus ventralis lateralis and lies lateral to the ventral half of the caudal portion of nucleus centralis lateralis. In some sections the ventral tip of nucleus centralis lateralis intervenes between the oral portion of centrum medianum and the dorsomedial nucleus (fig. 4). In its caudal portion, nucleus centralis lateralis is inconstant and varies greatly in size. Expansion of nucleus lateralis posterior ventrally, medial to nucleus ventralis posteromedialis, makes it the sole lateral boundary of nucleus centralis lateralis. Nucleus centralis lateralis then diminishes rapidly in size and finally ends at the level of the caudal pole of nucleus paracentralis. Its cells are somewhat more faintly staining, but similar to those of the paracentral nucleus.

Nucleus parafascicularis ( $f i g .6$ ). This nucleus lies medial to centrum medianum, separated from it by an inconstant fibrous layer, and lateral to the periventricular gray and posterior paraventricular nucleus throughout its extent. Its oral pole is near the junction of the oral and middle thirds of centrum medianum. Caudally it blends with the nucleus limitans. It appears first as thin cords of darker staining cells in the dorsomedial portion of centrum medianum and expands caudally to reach its greatest development at the level of the habenulo-peduncular system, which runs through it and divides it into lateral and medial parts. Dorsally and ventrally it is surrounded by fibers of the internal medullary lamina. The nucleus of the habenulo-peduncular system is in relation to the dorsomedial portion of the parafascicular nucleus. It is a very compact nucleus, the cells of which are small, globular and very deeply staining. The caudal pole forms the most medial portion of the ventral border of the thalamus.

Centrum medianum ( $f g s .4,5,6,7$ and 8). This is a large, intralaminar nucleus,. which extends from about the caudal border of massa intermedia to a point just rostral to the caudal extremity of the habenula. Orally the internal medullary lamina splits to surround it completely.

The rostral pole is a small, oval, lightly-staining, relatively cell-poor mass, situated between the dorsal tip of nucleus ventralis posteromedialis and the dorsomedial nucleus, with its long axis in the plane of the internal medullary lamina (fig. 4). The dorsal tip is directed somewhat laterally and penetrates the dorsal portion of nucleus ventralis lateralis. As the nucleus expands caudally it forms a crescent-shaped mass of cells, with its medial tip almost in apposition to nucleus paracentralis. The dorsal tip expands dorsally and lies in the substance of nucleus lateralis posterior, which has here replaced the dorsal portion of nucleus ventralis lateralis. In a few sections the caudal part of nucleus centralis lateralis expands ventrally and, interposes itself between the dorsomedial nucleus and centrum medianum. Ventral and lateral to centrum medianum is nucleus ventralis posterior medialis (fig. 5).

Farther caudally the nuclei paracentralis and centralis lateralis drop out, and centrum medianum expands medially, becoming pear-shaped and extending to the periventricular gray. The cells are concentrated in the medial half of the nucleus.

Centrum medianum becomes more cellular caudally, its ventrolateral portion being the last part to lose its fibrous character (fig. 5). The medial tip of cen- 
trum medianum is related to the posterior paraventricular nucleus for a short distance, before it is replaced by nucleus parafascicularis. Caudally the nucleus becomes almost spherical and lies more horizontally. The medial division of the pulvinar, which has replaced nucleus lateralis posterior, expands ventrally and forms an ever greater cap around the lateral portion of centrum medianum, intervening between it and nucleus ventralis posteromedialis (fig. 6). As the medial division of the pulvinar replaces the dorsomedial nucleus, the former constitutes the entire dorsal and lateral boundary of centrum medianum. As nucleus ventralis posteromedialis disappears, the ventral border of centrum medianum forms part of the ventral border of the thalamus, between the medial division of the pulvinar laterally and nucleus parafascicularis medially.

Centrum medianum is composed of faintly-staining, medium-sized, polymorphous cells, concentrated medially and around the borders of the nucleus, where they tend to orient themselves in the direction of the fibers.

Nucleus dorsomedialis (figs. $3,4,5,6$ and 7 ). This is one of the largest nuclei in the thalamus. It occupies the dorsomedial portion of the central half of the thalamus, extending from the point of greatest development of the anteromedial nucleus to a level a few sections rostral to the caudal pole of nucleus ventralis posterior lateralis.

The oral portion of the dorsomedial nucleus is well demarcated by a fibrous capsule, the anterior paraventricular nucleus intervening between it and the ventricular wall. It enlarges rapidly to replace almost the whole anteromedial nucleus. The internal medullary lamina, containing the lateral central and paracentral nuclei, is lateral and ventral, and the anterior paraventricular and parataenial nuclei are medial to it, separating it from the ventricular wall. The persistent dorsal portion of the anteromedial nucleus is separated from the dorsomedial nucleus by a distinct fibrous capsule, a branch of the internal medullary lamina. Elsewhere the dorsomedial nucleus is delineated only cytoarchitecturally. The oral pole of nucleus submedius is situated at the ventromedial corner of the dorsomedial nucleus, but it soon shifts medialward and is separated from the dorsomedial nucleus by nucleus rhomboidalis.

Caudally the dorsomedial nucleus expands. Caudal to the anteromedial nucleus, the anteroventral nucleus lies dorsal, and later is replaced by nucleus lateralis dorsalis. In this plane nucleus paraventricularis anterior is a thin vertical strip which lies medial to the nucleus under consideration, and the bulk of the parataenial nucleus is pushed dorsalward by the increase in size of stria medullaris thalami.

Lateral and ventral to the internal medullary lamina and its intralaminar nuclei, the dorsomedial nucleus is in relation to nucleus ventralis lateralis. As nucleus lateralis posterior appears, it lies laterally and dorsally, with nucleus centralis lateralis intervening. The dorsomedial nucleus continues to enlarge uniformly and, eaudal to massa intermedia, it forms about one-half of the total cellular mass of the thalamus (fig. 4). Nucleus ventralis posterior medialis replaces nucleus ventralis lateralis and lies lateral and ventral to the dorsomedial nucleus, but caudally centrum medianum and nucleus parafascicularis occupy this position (figs. 5 and 6 ).

Caudal to the nuclei rhomboidalis, paracentralis and centralis lateralis, the dorsomedial nucleus shrinks. The caudal expansion of stria medullaris thalami in- 
dents the dorsomedial portion of the dorsomedial nucleus, and the parataeniai nucleus shifts to an entirely dorsal position. As the habenula is approached, the lateral and dorsal borders of the dorsomedial nucleus become more indistinct, and, at the level of the habenula, the medial portion of the pulvinar intermingles with the cells of the dorsomedial nucleus (fig. 5). Centrum medianum and nuclcus parafascicularis enlarge and replace the ventral portion of this nucleus.

The habenulo-peduncular tract encroaches on the medial portion of the dorsomedial nucleus, and the nucleus of the habenulo-peduncular tract mingles with the medial portion of this nueleus (figs. 6 and 7 ). The medial division of the pulvinar gradually replaces the dorsomedial nucleus dorsally and laterally (fig. 6).

The dorsomedial nucleus is composed of two distinct cell types. One has a large, polymorphous, deeply-staining cell body with a pinkish-red tinge and many processes. The other is smaller, lighter staining, with a brownish-red tinge, globular with a tendency to pyramidization. Both contain some deeply-staining, indefinite tigroid granules near the periphery. The magnocellular type forms a peripheral coating around the smaller-celled internal nucleus. This coating is not complete or equally developed everywhere. It is well marked orally, medially and dorsomedially and merges with the periventricular gray medially and the paracentral nucleus ventromedially. Ventrolaterally there are occasional clusters of these cells. A small cluster of cells is usually seen in the dorsomedial corner of the dorsomedial nucleus (figs. 3 and 4), but near the caudal pole small magnocellular strands appear laterally (fig. 5) and form the extreme caudal pole of the nucleus, merging with the nucleus of the habenulo-peduncular tract medially and the pulvinar laterally. The magnocellular portion is sometimes well demarcated, but usually it mingles with the internal nucleus. The cells are arranged as though they were interposed between fibers, and their long axes vary. Rostrally they lie with their long axes in a rostrocaudal plane. Prongs of cells penetrate the internal nucleus from this layer, the most prominent lying in the caudal third of the nucleus, running ventrolaterally from the dorsomedial portion of the magnocellular part to form a small part of the laterodorsal border of the dorsomedial nucleus. The magnocellular portion of this nucleus is very similar to the paracentral nucleus. The cells are much the same in appearance and arrangement, and, in sagittal sections, the two nuclei appear to be continuous (fig. 7). The magnocellular part is structurally similar to the intralaminar nuclei. The relationships of this portion of the dorsomedial nucleus are best seen in sagittal sections.

The internal portion of the dorsomedial nucleus consists of a more compact ventromedial portion and a less compact lateral part traversed by horizontal fibers (fig. 4). There is a dark and a light staining variety of cells. The caudal part of the dorsomedial nucleus consists entirely of this more compact ventromedial portion.

Nucleus of the habenulo-peduncular tract (figs. 6 and 7). This nucleus extends from a point a short distance rostral to the habenulo-peduncular tract to nucleus limitans. The oral pole intervenes between the habenular complex and the dorsomedial nucleus (fig. 6). In its caudal expansion it replaces the medial portion of the dorsomedial nucleus. At first the habenulo-peduncular tract lies entirely medial to its nucleus, but caudally there are some cells in- 
terposed among the fibers. Caudal to the habenulo-peduncular tract the the nucleus fades into the dorsal portion of nucleus limitans.

This nucleus consists of deeply staining, large, polymorphous cells with many processes. Cells in and near the habenulo-peduncular tract have the appearance of being arranged between bundles of fibers. The nucleus is well demarcated from the habenular complex, but its cells mingle with those of the dorsomedial and parafascicular nuclei.

\section{Posterior group}

Pulvinar (figs. 5, 6, 7 and 8). This is the caudal continuation of nucleus lateralis posterior, and the caudal pole of nucleus lateralis dorsalis joins it. It extends from a plane through the rostral pole of the habenular complex to the caudal tip of the thalamus. It can be divided into three parts : lateral, medial and inferior.

The lateral part of the pulvinar lies dorsal to the lateral geniculate nucleus, the inferior part between the medial and lateral geniculate nuclei ; the remainder forms the medial part of the nuclear mass. The lateral part has many fibers (transversely cut in cross-sections) intermingling among the cells, but the medial and inferior divisions are more compact. The neurons constituting the pulvinar - and especially its lateral division - are of the same type as those of nucleus lateralis posterior.

At its oral boundary the pulvinar consists only of lateral and medial divisions. Caudally it expands medially to replace the dorsomedial nucleus and centrum medianum. The ventral expansion of the pulvinar intervenes between the caudal poles of the nuclei posterior medialis and lateralis, which it later replaces (fig. 6). The lateral division of the pulvinar also expands ventrally on the lateral side of nucleus ventralis posterior lateralis.

Nucleus suprageniculatus. This nucleus lies along the dorsal and medial margins of the oral part of the medial geniculate nucleus. It projects dorsally for some distance into the pulvinar. It is very small in rostrocaudal extent, being present in only two or three sections. It is distinguished by its large, darkly staining cells.

Nucleus limitans. This is a narrow band of large, deeply staining cells, extending along the ventromedial border of the caudal portion of the thalamus. Its rostral pole is found in a plane through the caudal end of the nucleus of the habenulo-peduncular tract dorsally and of nucleus parafascicularis ventrally. It extends obliquely from the ventrolateral corner of the caudal third of the habenular complex around the medial border and medial part of the ventral border of the pulvinar, almost to the medial geniculate nucleus. A few sections in front of the caudal pole of the pulvinar, with the appearance of the typical cytoarchitecture of the superior colliculus, nucleus limitans disappears. Medial and ventral to it are the pretectal group of nuclei, and lateral and dorsal is the medial division of the habenula.

Grünthal ('34) subdivided the pulvinar into more parts than are described here. The description given coincides with that for Macaca, mulatta by Walker. Crouch ('34) further divides the medial nucleus of the pulvinar, and so do Vogt ('09) and Friedemann ('12) in Cercopithecus, but the general description is the same. 


\section{DESCRIPTION OF DEGENERATED MATERTAL}

\section{Thalamic degenerations}

Three cases of thalamic degeneration following cortical destruction are described. The first presents a more or less diffuse cortical degeneration, the second a lesion in the territory of distribution of the middle cerebral artery, extending deeply to the ventricle and into the white matter of the temporal lobe. These two cases form a group in which practically all the cortical connections of the thalamus have been destroyed. Since the basal ganglia in the first case are normal and in the second only slightly affected, these cases also permit a differentiation between thalamo-cortical and thalamo-striate connections in respect to some of the nuclear elements of the thalamus. The third case presents a defect which includes the anterior limb of the internal capsule at the level of the oral pole of corpus striatum and destroys the thalamocortical connections with the frontal area.

Case L.B. L.B., a white female, aged 18 months, developed "an upper respiratory infection" 2 weeks previous to admission. Four days before admission, she had two grand mal attacks, followed by weakness of the right arm and right leg. Examination revealed bilateral otitis media and right hemiplegia. The spinal fluid was negative. The patient improved and was discharged in 20 days with only slight residual weakness of the right side. She continued to have convulsions for an indefinite period of time. At the age of 4 years, she suffered from "choking spells," and an encephalogram taken at this time showed generalized cortical atrophy. At the age of 5 years the patient died in status epilepticus, following mastoidectomy.

Her brain, which weighed $1100 \mathrm{gm}$., was soft, and the convolutions were extremely atrophic in both hemispheres and in all lobes. In coronal sections the gmy matter was thin, particularly in the frontal lobes, less so in the occipital lobes. The white matter was very edematous, and the ventricles were moderately enlarged. The corpus callosum and both fornices were partially atrophic. There was degeneration in both fronto-pontile tracts extending from the cortex to the pons. The superior fronto-occipital bundles were degenerated also, and there was slight demyelinization of the temporal lobes. The basal ganglia, the medulla oblongata and the cerebellum were normal. The thalamic degenerations are shown in the table.

There was a widespread cytoarchitectural disturbance of the cortex. In the rostral half of the frontal and cingulate gyri, first and second temporal gyri, the dorsal portion of the third temporal gyrus, and Sommer's sector of Ammon's horn there was almost total destruction of the neurons and the formation of a glial scar, or spongy state. Usually a few neurons remained in layer IV, and occasionally remnants, or nests of neurons, were seen in layers $V$ and VI. In other areas severe changes were confined to the supragranular layers, with but slight changes in the infragranular layers. This was evidenced in the motor cortex, where there was some disappearance of Betz cells and a severe falling out of the 
neurons of layers II and III, with replacement by glial scar tissue. The hippocampal and fusiform gyri, the area parastriata (OB of von Economo), the caudal third of the inferior frontal gyrus and the ventral portion of the inferior temporal gyrus showed minimal changes, consisting of some decrease of neurons in layers II and upper III and an increase of glia. The calcarine area appeared unaffected. Apart from a moderate increase of glia, the white matter was unaffected.

In order to get a complete series of sections of the thalamus in Nissl stain, material from each side was utilized. Three blocks were eut: the rostral third of the left thalamus, the middle third of the right thalamus and the left pulvinar. The pathology being equally distributed in extent and degree on both sides, it was felt that the differences between the two sides would not be important.

Case G.P. G.P., a white imbecile male, was admitted to the hospital at the age of 18 , because of frequent convulsions and irritability. According to his mother, his development was retarded. Convulsions were said to have occurred first at 3 months. There was a sudden onset of a left hemiplegia at the age of $1 \frac{1}{2}$ years. At the age of 9 years, examination revealed a left hemiplegia, anisocoria and non-reactive pupils. The blood serology was positive; the spinal fluid equivocal. An encephalogram performed at the age of 20 showed generalized brain atrophy with a large cyst in the right hemisphere. The patient died 3 years later of inanition and terminal bronchopneumonia.

The brain was small and weighed $900 \mathrm{gm}$. There was a large cystic lesion covered by thickened meninges on the convexity of the right hemisphere, involving the entire insula, the opercular regions and the adjacent gyri in the frontal, parietal and temporal lobes. Although the lesion involved the territory of the middle cerebral artery, this vessel and the other basal arteries appeared normal. The left cerebellar hemisphere was also atrophic.

Coronal sections revealed that the lesion penetrated deeply into the white inatter of the hemisphere, almost to the wall of the dilated ventricle. It involved the internal capsule, giving rise to the following secondary degenerations: (1) The right thalamus - see table. (2) The right pyramidal and fronto-pontocerebellar tracts. (3) The left cerebellar hemisphere, where there was diffuse degeneration of the hemisphere and the superior vermis. The inferior vermis, the tonsil and the flocculus were normal. The left dentate nucleus and the left middle cerebellar peduncle appeared atrophic. (4) The right inferior olive appeared to be reduced in size. All the ventricles were moderately distended, the right lateral ventricle markedly so ; the corpus callosum was atrophic.

Brain blocks of the whole hemisphere were stained alternately with Nissl and Weigert-Pal stains. Blocks containing the thalamus were cut serially. The rostral part of the thalamus was stained with Nissl stain, and the caudal part with Weigert. Sections were eut from both sides of all other blocks.

Examination of these sections revealed that in the frontal area, rostral to the temporal lobe, the lesion involved the ventral half of the middle frontal, the inferior frontal and the lateral orbital gyri. Caudally the lesion destroyed the entire insula, the parietal operculum and cut deeply into the temporal operculum, involving the medial portions of the transverse temporal gyri, and small areas of the medial part of the superior temporal gyrus. In the temporal lobe the defect cut into the white matter in a $\mathrm{V}$-shape with its apex pene- 
trating to the depth of the superior temporal sulcus and affecting the dorsal portion of the external sagittal stratum and the dorsal thalamo-occipital fibers. Completely destroyed also were the external capsule, the claustrum, the lateral portion of the caudate nucleus and the putamen. The area involved extended almost to the ventricular wall, destroying the fibers of the corona radiata but sparing a few of its periventricular fibers and some of the cortico-spinal tract. Caudal to the insula, the lesion extended into the parietal lobe for a short distance. There was partial atrophy of the right medial geniculate body and partial degeneration of the right acoustic radiation. There was a thin zone of degeneration in the lateral portion of both optic tracts and both lateral geniculate bodies. A small ventral portion of both geniculo-calcarine tracts was also degenerated (figs. 15 and 19).

The cerebral lesion consisted of an intricate network of glial scars with pseudocystic degeneration of the gray and the white matter. The process was in the end stage, and there was no longer any histological evidence of vaseular etiology. There was a degeneration of Sommer's sector of the right Ammon's horn. Elsewhere the cortex showed slight changes. There was a small infarct in the left insula, and the cells of layers II and upper III, were somewhat shrunken.

Case H.M. (age 41). The clinical history of this patient is very meager. He was an inmate of a state prison for many years before his death, and a chronic invalid. Autopsy revealed an old heart disease of unknown origin and evidences of old, healed infarets.

There was an old softening of the right hemisphere of the brain, involving the caudal portion of the inferior frontal gyrus and the adjacent insula. Another area of softening involved the superior surface of the right cerebellar hemisphere. The cortico-spinal tract appeared intact, but the fronto-ponto-cerebellar tract was degenerated. Thalamic degenerations are described in the table.

The brain was cut into blocks and treated for staining by the Weigert-Pal technique. The blocks containing the thalamus were cut serially. Some sections were cut from all the other blocks. Examination of these sections revealed that rostrally the lesion created a defect occupying the ventral half of the inferior frontal gyrus and the white matter deep to it, the adjacent part of the insula and the lateral orbital gyri. The demyelinization extended into the white matter of the second frontal gyrus, almost to the dilated anterior horn of the lateral ventricle and involved part of the forceps minor of the corpus callosum. The right half of the corpus callosum was slightly atrophic in this position. Caudally the demyelinization involved the lateral portion of the anterior perforated space, and the defect extended to the lateral border of the oral pole of the corpus striatum. The demyelinization involved the anterior limb of the internal capsule (fig. 21). The oral portion of the external capsule was degenerated and part of the corpus callosum was still involved. Caudally the lesion shrank rapidly, so that, at the level of the genu of the corpus callosum, it was confined to a small cherrysized area of demyelinization in the subcortical white matter.

The lesion affected only the rostral portion of the anterior limb of the internal capsule. The oral poles of the corpus striatum and the external medullary lamina were degenerated. The fronto-ponto-cerebellar tract was completely degenerated. The cortico-spinal tract appeared normal. 
Histological examination showed that the lesion was an old organized cystic softening, with extensive gliosis, old blood pigment and scant gitter cell reaction. Aside from some thickening of the arterioles, the vessels were normal.

A few neurons were seen in the anteroventral and anteromedial nurlej of cases L.B. and G.P. (figs. 9 and 17). In case L.B. this was due to the preservation of some nests of cortical cells, and in case G.P., to the sparing of a few of the most medial fibers of the anterior thalamic peduncle.

Nucleus ventralis anterior was almost completely degenerated in cases L.B. and G.P. (fig. 9). Only an occasional inflated or shrunken neuron was seen. In case H.M. the lesion involved only the rostral portion of the anterior limb of the internal capsule. The fibers of the dorsolateral portion of this nucleus run in the caudal portion of the anterior limb of the internal capsule, and consequently, this portion of the nucleus was spared (fig. 22).

Nucleus ventralis lateralis showed identical partial degeneration in cases L.B. and G.P. (figs. 11 and 18). Pars ventralis and the ventro-medial portion of this nucleus were preserved, but higher magnification showed that even in these portions there was a lack of small neurons. In the remaining part of the nucleus an occasional large cell was seen, but the small neurons were almost all gone. Some of the large neurons, particularly in the dorsal and dorsomedial portions of the nucleus, appeared a little shrunken and stained deeper than normally. Their tigroid granules were not so distinct and stained unusually deeply, but in general were well preserved. Degeneration of this nucleus appears to affect primarily the small-celled element. In case H.M., only the medioventral portion appeared degenerated (fig. 23).

Because of the shrinking of the thalamus and the destruction of normal landmarks, nucleus ventralis intermedius could not be recognized. In cases L.B. and G.P., nucleus ventralis posterior medialis showed changes primarily affecting its small neurons (figs. 12 and 13). In the oral portion, where the large neurons are somewhat smaller and comparatively few; there was a fair amount of gliosis. With higher magnification, large neurons were seen among the scar tissue. Their cell bodies were somewhat paler and their Nissl bodies fainter and indistinct at times, but there did not seem to be any appreciable disappearance of cells. Practically no small neurons were seen. More caudally the nucleus became more cellular and distinct. The larger neurons, in the main, had the normal staining characteristics and appeared to be present in normal numbers. There was a falling out of small neurons, however, and many of them were shrunken and degenerated. Although there was some gliosis in this portion of the nucleus, it did not decrease much in size, and the gliosis was less intense than orally.

The changes in the form and content of the nucleus ventralis posterior lateralis were the same in cases L.B. and G.P. and were consequent to small cell degeneration and falling out. Normally the oral portion of this nucleus is cell poor and contains a large proportion of fibers. There was considerable gliosis in the oral portion in these cases. With a high magnification, however, the large neurons of this section could be seen. Some showed slight changes in their staining reactions, but in general they were well preserved. More caudally the nucleus reached almost its normal size. The large neurons increased in size and stained normally. There was considerable disappearance of small neurons, but the gliosis 


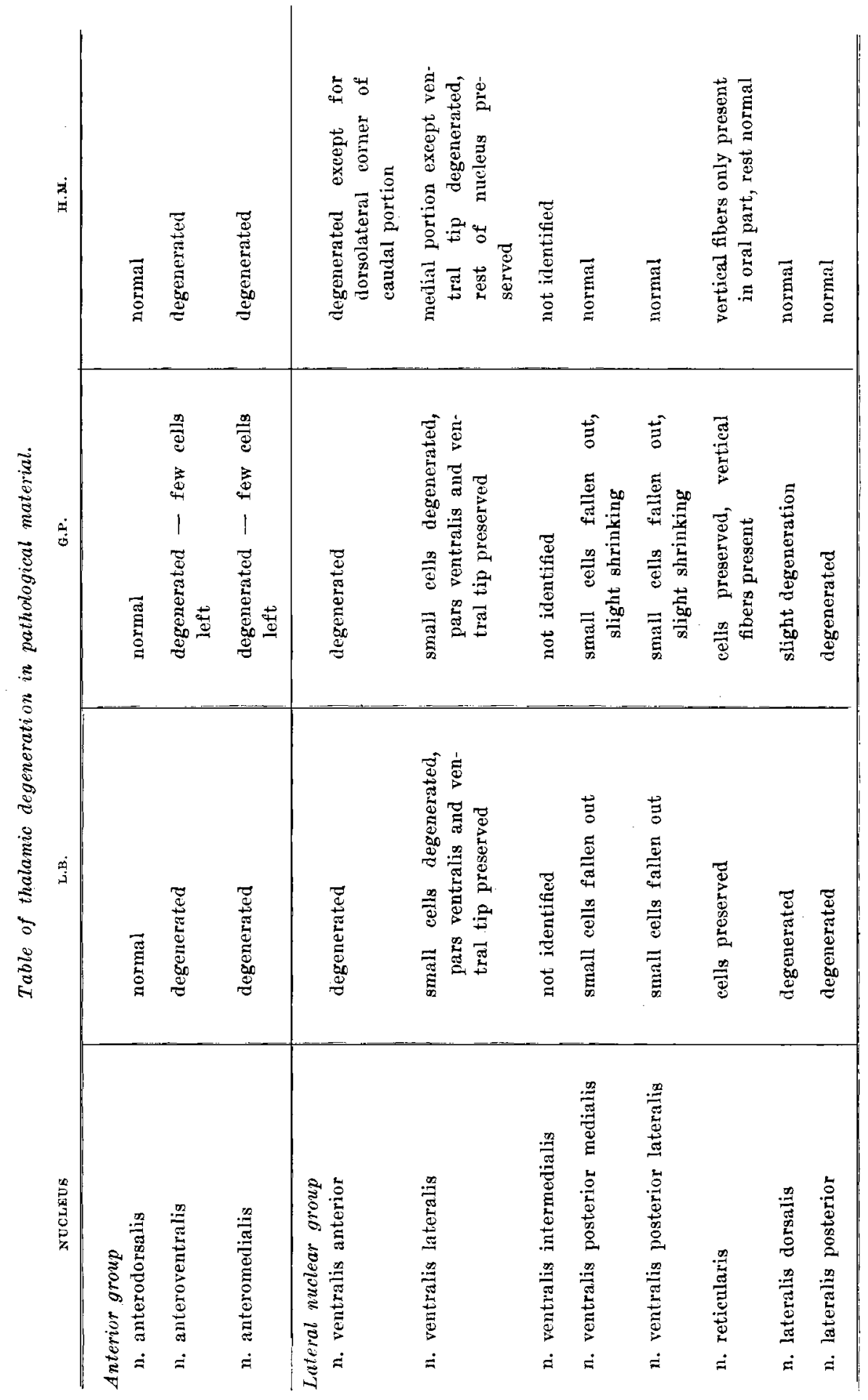


THE HUMAN THALAMUS

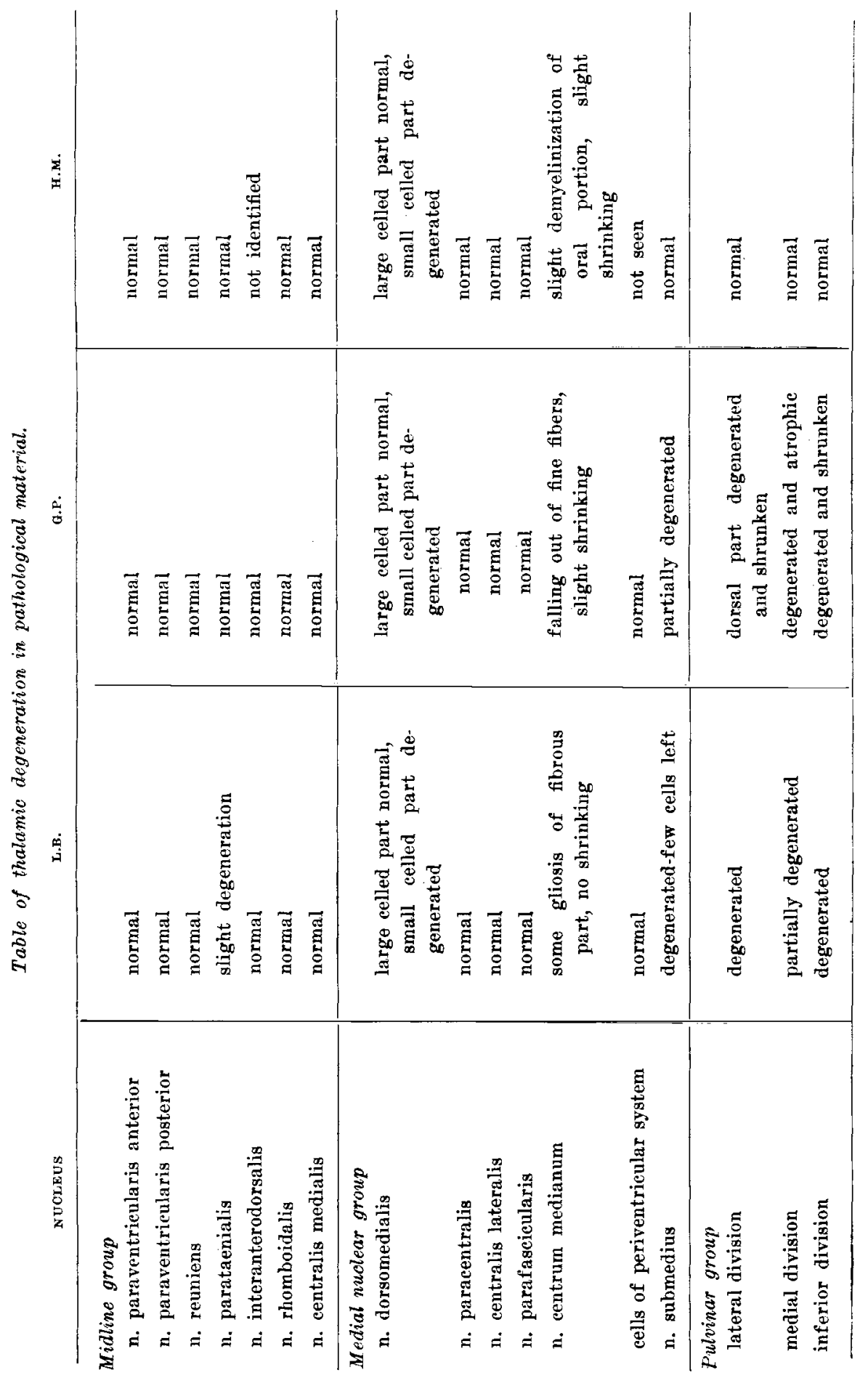


was much diminished. In case G.P. the network of fibers of both ventral posterior nuclei was more dense (figs. 19 and 20).

The variability in development of the midline group of nuclei in man made the assessment of a disappearance of neurons a difficult task. The number and state of neurons and the amount of gliosis were taken into consideration in deciding this question. The amount of gliosis in itself can give only a relative idea of the amount of destruction of fibers. The blocks in case H.M. were from both hemispheres. Thus we had a series of the normal thalamus stained with the Weigert-Pal technique. Weigert-Pal sections through the oral part of the right thalamus of case L.B. were available, and the caudal half of the thalamus of case G.P. was stained by this technique. The results were obtained by comparing the pathological Nissl and Weigert sections with the normal.

Cases similar to L.B. have been described by Le Gros Clark and D. S. Russell ('40) and by Déjerine ('01). The former described a case of degeneration of the left cerebral hemisphere which spared the following: the anterior twothirds of the cingulate gyrus, the uncus and adjacent medial part of the hippocampus, including the dentate gyrus, a narrow strip of the interior temporal convolution, the lips of the calcarine fissure and the terminal $1.5 \mathrm{~cm}$. of the occipital pole. The difference between their study and the present report is the finding by Le Gros Clark and Russell of degeneration of the reticular, paracentral and central lateral nuclei and complete degeneration of the ventral nucleus, except in the caudal part of the thalamus, where they found "a slender strand of scattered cells extending dorsolaterally through the regions of the ventral nucleus." In the case of Pradel (p. 100), Déjerine described cortical destruction of the left cerebral hemisphere involving the whole convexity, the medial portion of the superior frontal gyrus, and the orbital surface of the frontal lobe. His results are similar to those reported for L.B.

Papez, Bull and Stotler ('40) and Déjerine ('01) described cases similar to G.P. The former reported a lesion of the left lenticulo-striate artery involving the lower parietal and upper temporal gyrus, insula, claustrum and corpus striatum. The lesion extended deeply into the white mattex, disconnecting the thalamus from the cortex. They found the whole thalamus atrophied and devoid of cells. The terminal neuropil of afferent tracts was present.

In the case of Rivaud (p. 131) Déjerine described a lesion involving the opereular portions of the inferior frontal, superior temporal, supramarginal and central gyri, and insular and retro-insular portions of the convexity. The defect extended deep into the hemisphere, reaching the ventricle dorsal to the caudate nucleus, and cut all connections of the thalamus. He found degeneration in the thalamus similar to that described for G.P.

Walker's findings in Macaca mulatta, after almost complete ablation of the cortex, differ from those in cases G.P. and L.B. He found the anterodorsal nucleus severely degenerated and complete degeneration of the nuclei ventralis lateralis and ventralis posterior medialis and lateralis. The nucleus ventralis anterior was intact.

The persistence of the large neurons of the nuclei ventralis lateralis, ventralis posterior medialis and ventralis posterior lateralis described here after severance of cortical connections was also found by Déjerine ('01, p. 356), who states, "Dans les vastes et anciennes lésions corticales (Cas Pradel, p. 100; Rivaut, p. 
151) la dégénérescence peut être complèt dans la moité dorsal du noyeau externe, mais elle est toujours partielle dans la moité ventral qui reçoit surtout le contingent des fibres strio-thalamique." The illustrations of Papez, Bull and Stotler show only simple shrinking of the pars ventralis of nucleus ventralis lateralis and nucleus ventralis posterior medialis and lateralis. They used the unsatisfactory carmine cell stain. There is only one photomiorograph in the paper by Le Gros Clark and D. S. Russell, particularly to show the preserved neurons of the centrum medianum. However, in this photomicrograph some preserved large neurons are visible in the adjacent nucleus ventralis posteriomedialis. The finding of preserved large neurons in the ventral nuclei after severing of cortical connections is of particular interest, for this. would seem to afford a ready anatomical explanation for the preservation of some types of sensation in man with hemidecortication or lesions of the parietal lobe, as reported by Dandy ('33), Gardner ('33) and Head ('20). It also indicates the anatomical level of consciousness in man, for lesions of the sensory pathways caudal to the thalamus result in complete loss of sensation. It seems reasonable to assume that these large neurons, by virtue of their close anatomical relationship to the afferent sensory tracts, are the anatomical site of consciousness. It would also appear that they form most of the thalamo-striate connections.

Déjerine ('01) deseribed a case similar to H.M. (Cas Moriceau, p. 148). The lesion involved the middle thirds of the ventral half of the middle frontal and the inferior frontal gyrus of the right cerebral hemisphere, extending deeply into the white matter, almost to the ventricle immediately in front of the oral pole of the striatum. There was degeneration of the anterior limb of the internal capsule, the anterior extremity of the external nucleus and all of the dorsomedial nucleus: Von Monakow (1895) also reported a case similar to H.M. In case 1 the defect occupied the whole of the inferior frontal gyrus and the lateral half of the middle frontal gyrus. It extended deeply into the white matter, involving the oral part of the striatum and the dorsal two-thirds of the anterior limb of the internal capsule. The findings are the same as those reported in this study, except for the presence of degeneration of centrum medianum, the connections of which will be discussed in detail below. In case 2, von Monakow described a lesion which was greater in extent than that in H.M., but which did not cut off the fibers of the caudal portion of the posterior limb of the internal capsule. The defect involved the caudal half of the inferior frontal convolution, the opercular parts of the central gyri, the insula and first temporal gyrus. It extended deeply into the white matter, involving the dorsal third of the internal capsule at the level of the rostral pole of the striatum, the white matter of the middle temporal and supramarginal gyri, and the oral and dorsal portion of the putamen. Except for the degeneration of centrum medianum the findings agree with those described here. Stern ('42) reported the thalamic degenerations in man consequent to a lesion involving the middle thirds of the middle and inferior frontal convolutions, extending in depth about half way to the ventricle. He found complete degeneration of the rostral portion and of the medial third of the more caudal portion of the lateral nuclear mass to the level of centrum medianum, especially near the internal medullary lamina. All the small cells of the dorsomedial nucleus were affected. The darkly stained cells of medium size were preserved throughout. His findings, therefore, agree with those of the 
present study. This lesion was too rostral and ventral to involve the connections of the anterior nucleus. Fukuda ('19) described thirteen cases of thalamic degenerations in man consequent to lesions of the frontal area. His conclusions are that the dorsomedial nucleus projects to the caudal half of the middle frontal gyrus; centrum medianum to the caudal half of the inferior frontal gyrus; all the oral portion and medial third of the middle portion of the lateral nuclear mass projects to all the frontal area but has richest connections with the caudal portion; tuberculum anterius is partially connected with the frontal area, and its fibers run in the anterior limb of the internal capsule, but no definite local projection area is given.

Case H.M. is of particular interest because the defect is approximately at the site where the anterior limb of the internal capsule is sectioned in the operation by Freeman and Watts ('42) for the relief of certain types of mental disorder.

The connections of centrum medianum have been studied by $\mathrm{C}$. and $O$. Vogt ('41). In an exhaustive study of pathological human brains, they showed that destruction of the cortex or of projection fibers, or of the claustrum, pallidum, subpallidal and pallidal fibers did not lead to destruction of centrum medianurn, but that destruction of the striatum did cause its degeneration. They found that the putamen projects to the ventrolateral part of centrum medianum, and the caudate projects to its mediodorsal portion. Le Gros Clark and W. R. Russell ('39) described a case with a lesion of the insula and external capsule. In the middle of its extent the lesion involved the ventrolateral nart of the putamen. They stated that there was total degeneration of centrum medianum, but in the photomicrograph published in their paper, only partial degeneration of centrum medianum, as described in the first part of this paper, is apparent. In cases 1 and 2 of von Monakow, described above, the degeneration of centrum medianum may be explained by the poor technical methods and carmine stain, making differentiation of small neurons from glia cells difficult, and by the involvement of part of the striatum. The degeneration of centrum medianum in these cases was most likely only partial.

Papez ('37) and von Monakow (1895) described cases not similar to those presented in this paper, but confirming the findings of thalamo-cortical connections obtained here. In case 3 von Monakow deseribed a porencephalic defect of both central gyri almost to the dorsal border of the hemisphere, the anterior portion of the insula, and the supramarginal and first temporal gyri. The defect extended deeply to the ventricle, severing the fibers of the posterior limb of the internal capsule. The pulvinar, and the lateral and posterior ventral nuclei were degenerated. Papez reported a case which presented a cavity of the middle third of the right temporal lobe and the posterior parietal region, extending to the ventricle. The connections of the thalamus with the posterior parietal, temporal, parieto-occipital and temporo-occipital cortical areas were cut. The pulvinar and the lateral nuclei were degenerated.

\section{SUMMARY}

In general, the human thalamus shows the same differentiation of nuclei as those of higher primates. The differences are: the increase 
in relative size of the dorsomedial nucleus, the pulvinar and nucleus ventralis lateralis. The anterior group of nuclei, nuclei ventralis posterior and centrum medianum retain their relative proportions. The midline group of nuclei are present, but continuing their gradual diminution in the ascending phylogenetic scale, they are small and may be insignificant in man.

The dorsomedial nucleus possesses a magnocellular part which seems to be intimately connected with nucleus paracentralis and nucleus centralis lateralis. This would appear to evidence a greater richness of intranuclear connections, furthering thalamic integration. That the relative increase in size of the dorsomedial nucleus is related to the increase of the frontal granular cortex in man is indicated by the fact that most of its connections are with this frontal area.

The increase in size of nucleus ventralis lateralis, the recipient of the dento-thalamic and dento-rubro-thalamic fibers, is in accord with the increased development of the cerebellar hemispheres in man, and the growth of the pulvinar appears to be correlated with the inferior parietal and occipital association areas (area O.C. of von Economo).

After degeneration of the cortex or severance of cortical connections the following changes in the thalamus occurred.

I. There was complete degeneration of:

a. the nuclei anteroventralis and anteromedialis,

b. the internal, small celled portion of the dorsomedial nucleus,

c. nucleus ventralis anterior,

d. the pulvinar

e. the nuclei lateralis dorsalis and lateralis posterior.

II. Centrum medianum, and the reticular nucleus did not show an appreciable reduction of neurons, but there was a gliosis secondary to the degeneration of the fibers of passage.

III. Nuclei ventralis lateralis and ventralis posterior showed a falling out of the small neurons. The large neurons were preserved. $\mathrm{Nu}$ cleus submedius showed some reduction of neurons.

The cortical connections of nuclei anteroventralis, anteromedialis, dorsomedialis and the medial portion of nucleus ventralis lateralis run in the anterior limb of the internal capsule.

The preserved large cells in the nuclei ventralis lateralis and ventralis posterior medialis and lateralis may be the anatomical site of "protopathic sensation," and, along with centrum medianum, probably form the thalamo-striate connections. 


\section{LITERATURE CITED}

Aritins Kapprirs, C. U., G. CarL Huber and E. C, Crosery 1936 The comparative anatomy of the nervous system of vertebrates, including man. 2 vols., Macmillan Co., New York.

Balley, R., J. G. Dusser de Barrenne, H. W. Garl and W. S. MoCulloch 1940 Sensory Cortex of" Chimpanzee. J. Neurophys., vol. 3, pp, 469-485.

BaIley, P., S. Poliak and A. E. Walker 1935 The thalamic projection to the cerebral cortex in Macacus rhesus. J. Am. Neurol. Asso., vol. 61, pp. 48.

BECHTEREW, W. von 1887 Die Bedeutung der Sehhügel auf Grund von experimentellen und pathologischen Daten. Virchows Arch. f. Path. Anat., vol, 110, pp. 102-154; pp. $322-365$.

1894 Die Leitungsbahnen im Gehirn und Rückenmark. Leipzig: E. von Besold, pp. $x i i+210$.

1905 Über die sensible und motorische Rolle des Sehhügels. Monatschr. f. Psychiat. u. Neurol., vol. 17, pp. 224-231.

1906 Über die absteigenden Verbindungen des Thalamus. Neurol. Centralbl., vol. 25 , pp. 546-550.

Bodran, D. 1939 Studies on the diencephalon of the Virginia opossum. I. The nuelear pattern in the adult. J. Comp. Neur., vol. 71, pp. 259-323.

1940 Studies on the diencephalon of the Virginia opossum. II. The fiber connections in normal and experimental material. J. Comp. Neur., vol. 72, pp. 207-297.

1942 Studies on the diencephalon of the Virginia oppossum. Part III. The thalamo-cortical projection. J. Comp. Neur., vol. 77, pp. 525-575.

BUCX, P. C., AND H. KLÜver 1940 Anatomic changes secondary to temporal lobectomy, Arch. Neurol, and Psychiat., vol. 44, pp. 1142-1146.

BURDACH, K. F. 1819-1826 Von Baue und Leben des Gehirns. 3 vols., Leipzig Dyk'sehen Buchhandlung, vol. 1, p. 284, pl. 2 ; vol. 2, p. 418, pl. 7; vol. 3, p. 596 , pl. 1.

CAJAL, S. RAMóN Y 1909-11 Histologie du système nerveux de l'homme et des vertebrés. A. Maloine, Paris.

CRouch, RICHARD L. 1934 The nuclear configuration of the thalamus of Macacus rhesus. J. Comp. Neur., vol. 59, pp. 451-485.

DaNDY, WALTER E. 1933 Physiologieal studies following extirpation of the right cerebral hemisphere in man. Bull. Johns Hopkins Hosp., vol. 53, pp. 21-51.

DEJgrine, J. 1901 Anatomie des centres nerveux. J. Rueff, Paris.

von Economo 1927 Zellbau der Grosshirnrinde des Mensehen. J. Springer, Berlin.

Forx, C., AND J. Nrootessco 1925 Les noyaux gris centraux et la région mésencéphalo-sousoptique. Masson et Cie, Paris.

Freeman, E., and J. W. Warts 1942 Psychosurgery. Charles C. Thomas, Springfield, Ill.

FrimdemanN, M. 1912 Die Cytoarchitektonik des Zwischenhirns der Cercopitheken mit besonderer Berücksichtigung des Thalamus opticus. J. Psychol. u. Neur., Bd. 18, S. $309-378$.

FUKUDA, T. 1919 Über die faseranatomischen Beziehungen zwisehen den Kernen des Thalamus opticus und den frontalen Windungen des Mensehen. Sehweiz. Areh. Neur. u. Psychol., Bd. 5, S. 325-377.

GARDNER, JAMES M. 1933 Removal of the right cerebral hemisphere for infiltrating glioma. J.A.M.A., vol. 101, pp. 823-825.

GRÜNTHAL, E. 1934 Der Zellbau im Thalamus der Säuger und des Mensehen. J. Psyehol. u. Neur., Bd. 46, S. 41-112.

GURDJIAN, E. S. 1927 The diencephalon of the albino rat. J. Comp. Neur., vol. 43, pp. 1-114.

HEAD, H. 1920 Studies in neurology. Oxford University Press, London, vol. 2, p. 603.

$J_{A C O B}, C .1911$ Das Mensehenhirn. J. F. Lehmann, München.

Le Gros Clark, W. E. 1930 The thalamus of Tarsius. J. Anat., vol. 64, pp. 371-414.

1932 An experimental study of thalamic connections in the rat. Phil. Trans. Roy. Soc., London, s.B, vol. 222, pp. 1-28. 
LE Gros Clark, W. E. 1932a The structure and connections of the thalamus. Brain, vol. 55, pp. $406-470$.

1936 The thalamic connections of the temporal lobe of the brain in the monkey. J. Anat., vol. 70, pp. 447-464.

1937 The connections of the arcuate nucleus of the thalamus. Proc. Roy. Soc., London, s.B, vol. 123 , pp. 166-176.

LE GRos Clark, W. F., AND R. H. BogGoN 1932 On the connections of the anterior nucleus of the thalamus. J. Anat., vol. 67 , pp. 215-226.

1933 On the connections of the medial cell groups of the thalamus. Brain, vol. 56, pp. $83-98$.

1935 The thalamic connections of the parietal and frontal lobes of the brain in the monkey. Phil. Trans. Roy. Soc., London, s.B, rol. 224, pp. 313-359.

Lf Gros Clark, W. E., ANd D. C. W. Northfield 1937 The cortical projection of the pulvinar in the macaque monkey. Brain, vol. 60, pp. 126-142.

Le Gros Clark, W. E., AND D. S. Russell 1940 Atrophy of the thalamus in a case of acquired hemiplegia associated with diffuse porencephaly and sclerosis of the left cerebral hemisphere. J. Neur. and Psychiat., vol. 3 (new series), pp. 123-140.

Le Gros ClaARK, W. E., and W. R. Russhul 1939 Observations on the efferent connections of the center median nucleus. J. Anat., vol. 73, pp. 255-262.

Malone, E. F. 1910 Über die Kerne des menschlichen Diencephalon. Neur. Centralbl., Bd. 29 , S. $290-300$.

MetTler, Fred A. 1935 Corticifugal fiber connections of the cortex of Macaca mulatta. The occipital region. J. Comp. Neur., vol. 61, pp. 221-256.

$1935 \mathrm{a}$ Corticifugal fiber connections of the cortex of Macaca mulatta. The frontal region. J. Comp. Neur., vol. 61, pp. 509-542.

$1935 \mathrm{~b}$ Corticifugal fiber connections of the cortex of Macaca mulata. The parietal region. J. Comp. Neur,, vol. 62, pp. 263-291.

1935 e Corticifugal fiber connections of the cortex of Macaca mulatta. The temporal region. J. Comp. Neur., vol, 63, pp. 25-49.

1942 Neuroanatomy. C. V. Mosby Co., St. Louis.

Meyneri, T. 1872 Von Gehirne der Säugethiere. Stricker's Handbuch der Lehre von den Geweben des Menschen und der Thiere. S. von Engelmann, Leipzig.

voN MoNakow, C. 1895 Experimentelle und pathologisch-anatomische Untersuchungen über die Haubenregion, den Sehhügel und die Regio subthalamica, nebst Beiträgen zur Kenntnis früh erworbener Gross- und Kleinhirndefecte. Arch. f. Psychiat., Bd. 27, S. $1-128$ u. S. $386-478$.

PAPEZ, J. W. 1937 Connections of the pulvinar. Arch. Neur. Psychiat., vol. 41, pp. $277-289$.

1944 Struetures and mechanisms underlying the cerebral functions. Am. J. Psycol., vol. 57, pp. 291-316.

PAPE7, J. W., H. G. BULL AND W. A. STOTLER 1940 Cortical softening with atrophy of the internal capsule and dorsal thalamus. Arch. Neur. and Psychiat., vol. 44, pp. 977-989.

POLIAK, S. 1932 The main afferent fiber systems of the cerebral cortex in primates. University of Calif. Press: Berkeley, vol. 2, spp. xiv +370 .

RILeY, H. A. 1943 An atlas of the basal ganglia, brain stem and spinal cord. The Williams and Wilkins Co., Baltimore.

Rioch, D. M. 1929 Studies on the diencephalon of Carnirora. I. The nuclear configuration of the thalamus, epithalamus and hypothalamus of the $\operatorname{dog}$ and cat. J. Comp. Neur., vol. 49 , pp. $1-120$.

SACHS, E. 1909 On the structure and functional relations of the optic thalamus. Brain, vol. 32, pp. 95-186.

Spiegel. E. A., H. R. MilleR and M. J. Oppenheimer 1940 Forebrain and rage reactions. J. Neurophys., vol. 3, pp. 538-548.

Stern, K. 1942 Thalamofrontal projection in man J. Anat., vol, 76, pp. 302-307. 
Vogt, C. 1909 La myéloarchitecture du thalamus du cercopitheque. J. Psychol. u. Neur., Bd. 12. S. 275-324.

Vogt, C., AND O. Vogt 1941 Thalamusstudien I-IJI. J. Psychol. u. Neur., Bd. 50, S. 32-152. WALKER, A. E. 1934 The thalamic projection to the central gyri in Macacus rhesus. J. Comp. Neur., vol. 60, pp. 161-184.

1935 The retrograde cell degeneration in the thalamus of Macacus rhesus following hemidecortication. Ibid., vol. 62, pp. 407-419.

1936 An experimental study of the thalamo-cortical projection of the macaque monkey. Ibid., vol. 64, pp. 1-39.

1937 The thalamus in relation to the cerebral cortex. J. Nerv. and Ment. Dis., vol. 85, pp. $249-261$.

1938 The primate thalamus. University of Chicago Press.

Waller, W. H. 1934 Topographical relations of cortical lesions to thalamic nuclei in the albino rat. J. Comp. Neur., vol. 60, pp. 237-269.

WALLER, W. H., AND R. W. BARRIS 1937 Relationships of thalamic nuclei to the cerebral cortex in the cat. J. Comp. Neur., vol. 67, pp. 317-341.

Wexperow IC, 1 . 1915 Der Verlauf der sensiblen, akustischen und mancher anderer Systeme auf Grund eines Falles von Bluterguss in die basalen Femispharenalischnitte. Arch. f. Psychiat, vol. 55, pp. 486-520.

\section{ABBREVIATIONS}

ANT. COMM., anterior commissure

COR. CALL., corpus callosum

COR. LUY., corpus Luysii

CORT. SP. TR., cortico-spinal tract

FOR., fornix

FRON. PON. TR., fronto-pontine tract

INF. THAL. PWD, inferior thalamie pedunele

INT. CAP., interual capsule

LAT. GEN., lateral geniculate body

MAM. THAL. TR., mammillo-thalamie tract

MED. GEN., medial geniculate body

MID. N., midline nuejei

N. ANT. DOR., anterodorsal nueleus

N. ANT. MED., anteromedial nucleus

N. ANT. PARAVEN., anterior paraventricular nucleus

N. ANT. VENT., anteroventral nucleus

N. CAUD., caudate nucleus

N. CENM. MEDM., centrum medianum

N. CEN. LAT., nucleus centralis lateralis

N. CEN. MED, nucleus centralis medialis

N. DORSOMED., dorsomedial nucleus

N. HAB. LA'T., lateral habenular nucleus

N. HAB. MED., medial habenular nucleus

N. HAB. PED. TR., nucleus of habenulopeduneular tract

N. INTERANTERODOR., nucleus interanterodorsalis

N. LAT. DOR.. laterodorsal nucleus

N. LAT. POST., lateroposterior nucleus

N. LENT., lentiform nueleus

N. PARACEN., paracentral nucleus
N. PARAFASC., parafascicular nueleus

N. PARATEN., parataenial nucleus

N. PARAV. HYP., paraventricular nucleus of the hypothalamus

N. POST. PARAVEN., posterior paraventricular nucleus

N. RE'T., reticular nucleus

N. REUN., nucleus reuniens

N. RHOM., rhomboid nueleus

N. RUB., red nucleus

N. SUBMED., mucleus submedius

N. SUPRAG., suprageniculate nucleus

N. VENT. AN'T, ventral anterior nucleus

$\mathrm{N}$. VENT. LAT., ventral lateral nucleus

N. VENT. POST. INTER., intermediate posterior rentral nucleus

N. VENT. POST. LAT., lateral posterior ventrai nucleus

N. VENT. POST. MED., medial posterior ventral nucleus

P. MAGNOCELL., magnocellular part of dorsomedial nucleus

PALL., pallidum

PARS. VEN., pars ventralis of nucleus ven tralis lateralis

PERIV. FIB. AND CELLS, periventricular fibers and cells

PUT., putamen

PUL., pulvinar

STR. MED., stria medullaris thalami

TR. HAB. PED., habenulo peduncular tract

ZON. INC., zona incerta 


\section{PIJATES 1-20}

EXPLANATION OF FIGURES

1 to 6 Photomicrographs of coronal sections of the human thalamus (rostrocaudally). Nissl preparations (thionin).

7 and 8 Photomicrographs of sagittal sections of the human thalamus. Nissl preperations (thionin).

9 Case L.B. Photomierograph of a coronal section through the rostral portion of the anterior tubercle. Note the preservation of the nucleus anterodorsalis and nucleus reticularis. Compare with figures 1 and 2. Nissl preparation (thionin).

10 Case L.B. Photomicrograph of a coronal section through the rostral pole of the massa intermedia. Note the degeneration of the small-celled portion of nucleus dorsomedialis and the medial and dorsal portions of nucleus ventralis lateralis. The midline and other medial nuclei are preserved. Compare with figure 3. Nissl preparation (thionin).

11 Case L.B. Photomicrograph of a coronal section through the caudal portion of massa intermedia. Note the degeneration of the small cells of nucleus dorsomedialis, nucleus lateralis dorsalis and nuelus submedius. Pars ventralis of nucleus ventralis lateralis and the midline and other medial nuclei are preserved. Compare with figures 3 and 4 . NissI preparation (thionin).

12 and 13 Case L.B. Photomicrographs of coronal sections through the thalamus to show the preservation of the large neurons of nuelei ventralis posterior medialis and lateralis and the degeneration of nuclei lateralis posterior, lateralis dorsalis and dorsomedialis. The other medial and midline nuclei are preserved. Centrum medianum shows increased gliosis, but the neurons are preserved. Compare with figures 4 and 5. Nissl preparation (thionin).

14 Case L.B. Photomierograph of a coronal section through the pulvinar. Only seattered cells are seen. Nissl preparation (thionin).

15 Case G.P. Photomicrograph of a coronal section of the whole brain. The lesion involves the ventral portion of $\mathrm{F} 2, \mathrm{~F} 3$, the insula and the medial portion and white matter of T1 gyri. Weigert preparation.

16 Case G.P. (Left) Photograph showing degeneration of nuclei dorsomedialis. lateralis dorsalis and the dorsal portion of ventralis lateralis. Pars ventralis of nucleus ventralis lateralis is preserved. There is some shrinking of nucleus ventralis posterior medialis, and some shrinking, with demyelinization, of centrum medianum. (Right) Normal thalamus. Weigert preparation. $\times 2$.

17 Case G.P. Photomicrograph of a coronal section through the eaudal portion of the anterior tuberele, showing the preserved oral large eelled portion of nueleus dorsomedialis and the preservation of the midline, medial and anterodorsal nuclei. The other anterior nuclei and the dorsomedial portion of the nucleus ventralis lateralis are degenerated. Nissl preparation (thionin).

18 Case G.P. Photomicrograph of a coronal section eaudal to figure 17, showing preservation of pars ventralis of nucleus ventralis lateralis and of the midline nuelei. Nucleus anteroventralis, the small cells of nueleus dorsomedialis, and the dorsomedial portion of nueleus ventralis, lateralis are degenerated. Nissl preparation (thionin). 
19 Case G.P. (Left) Photograph showing the extent of the lesion in the temporal lobe. It involves the dorsal thalamo-oceipital fibers but spares the genieulo-calearine tract. There is preservation of the caudal portions of nuclei ventralis posterior, medialis and lateralis, with the entering lemnisei fibers, some shrinking and demyclinization of centrum medianum, and degeneration of nucleus dorsomedialis and the medial portion of the puvinar. Normal thalamus (right). Weigert preparation. $\times 1.5$.

20 Case G.P. Right. Photograph shows simple shrinking of centrum medianum and preserved caudal portions of nuclei ventralis posterior, medialis and lateralis, with the entering lemnisci fibers. There is degeneration of nucleus dorsomedialis, the medial part of the pulvinar and the medial genieulate body. Left: Normal thalamus. Weigert preparation. $\times 2$.

21 Case H.M. Photograph showing the extent of the lesion. It involves the white matter of F2, F3 and lateral orbital gyri, oral pole of the striatum and the anterior limb of the internal eapsule. Weigert preparation.

22 Case H.M. Photograph showing degeneration of nuclei anteroventralis and anteromedialis and preservation of nucleus anterodorsalis. Only the dorsolateral tip of nucleus ventralis anterior is preserved. Note caudal pole of lesion. Weigert preparation. $\times 1.5$.

23 Case H.M. Photograph showing degeneration of nuclei dorsomedialis, anteroventralis, and medioventral portion of ventralis lateralis. Weigert preparation. $\times 2$.

24 Case H.M. Photograph showing the degeneration of the nucleus dorsomedialis and some demyelinization of centrum medianum. Normal thalamus (left). Weigert preparation. $\times 2$. 


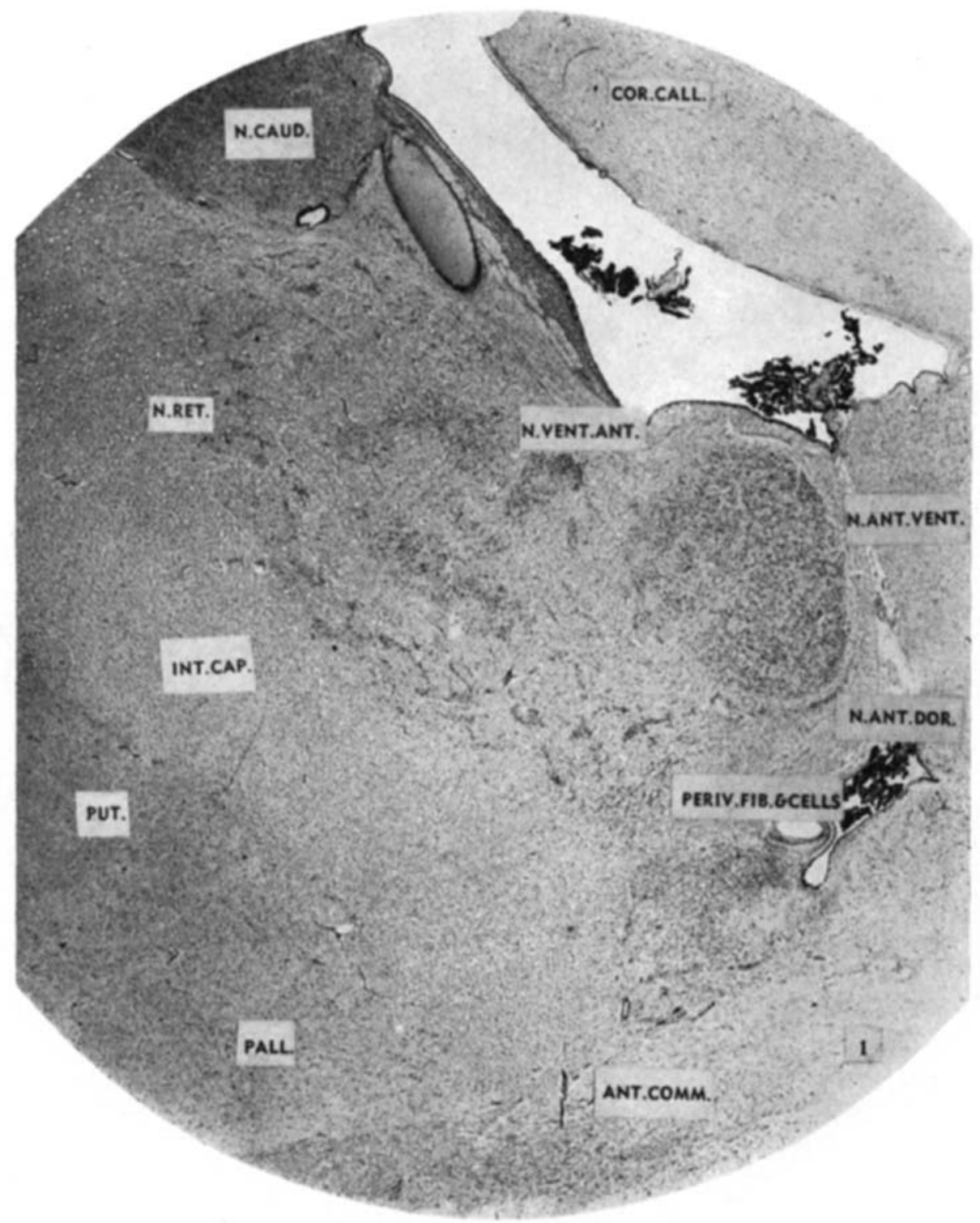




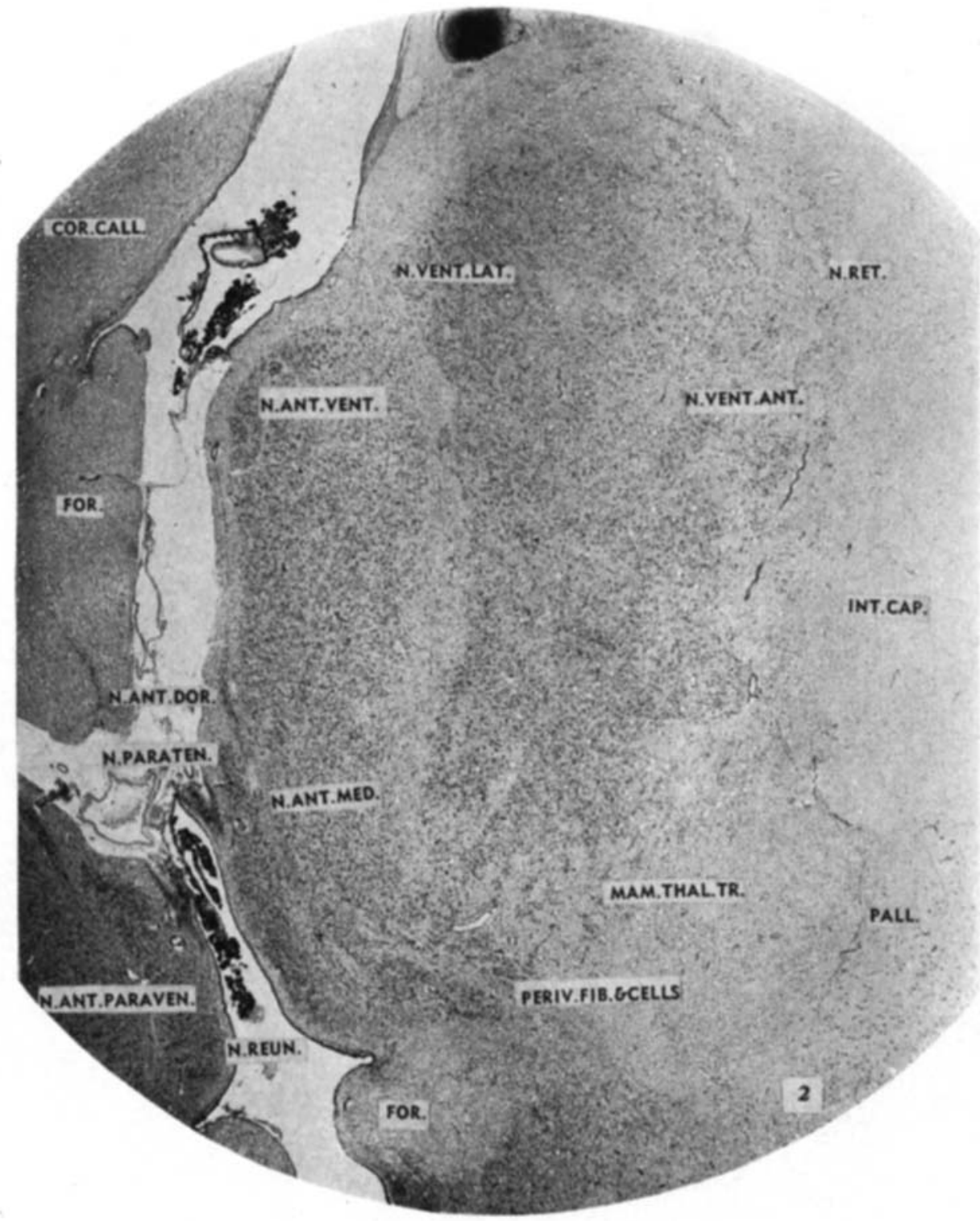




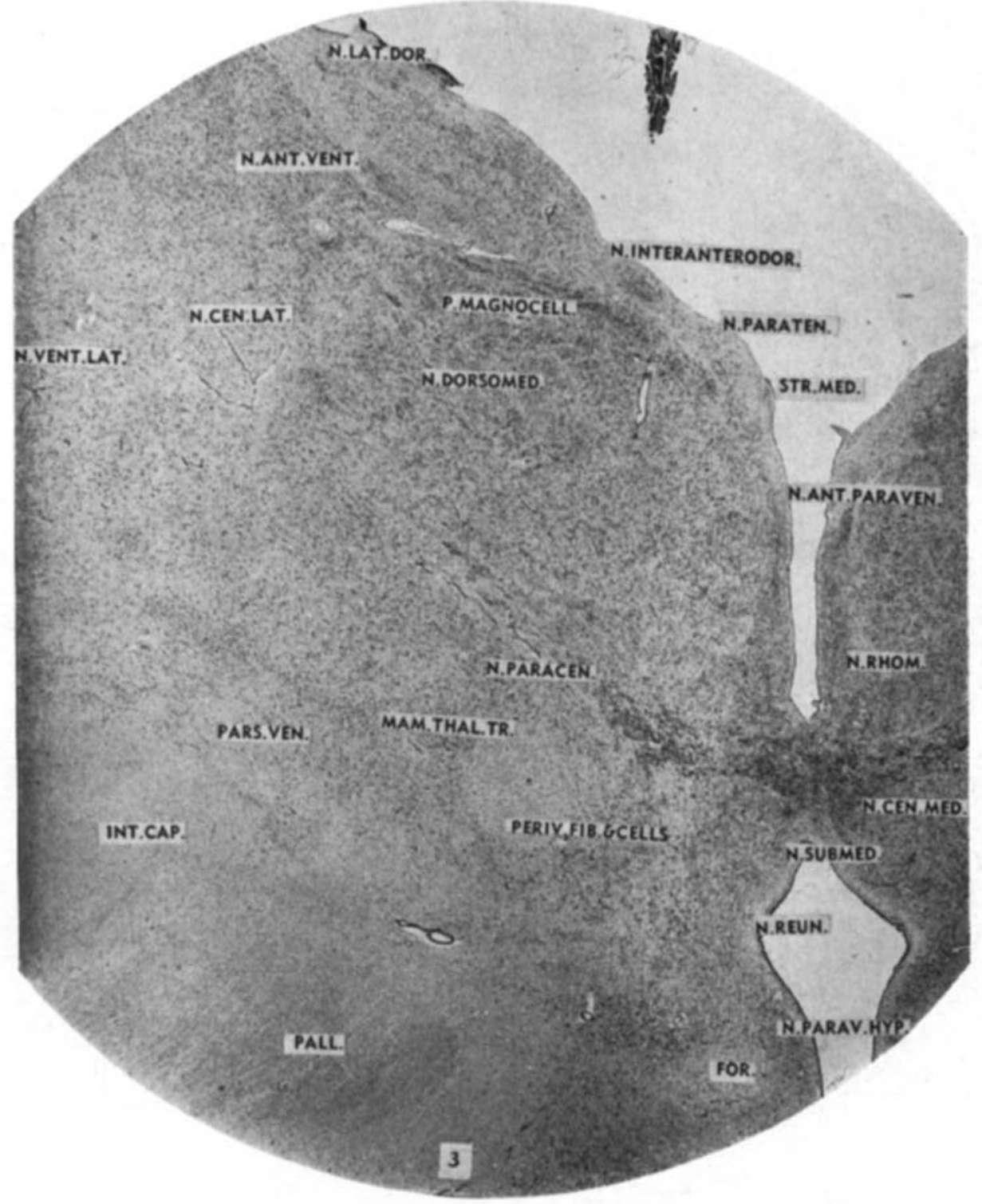




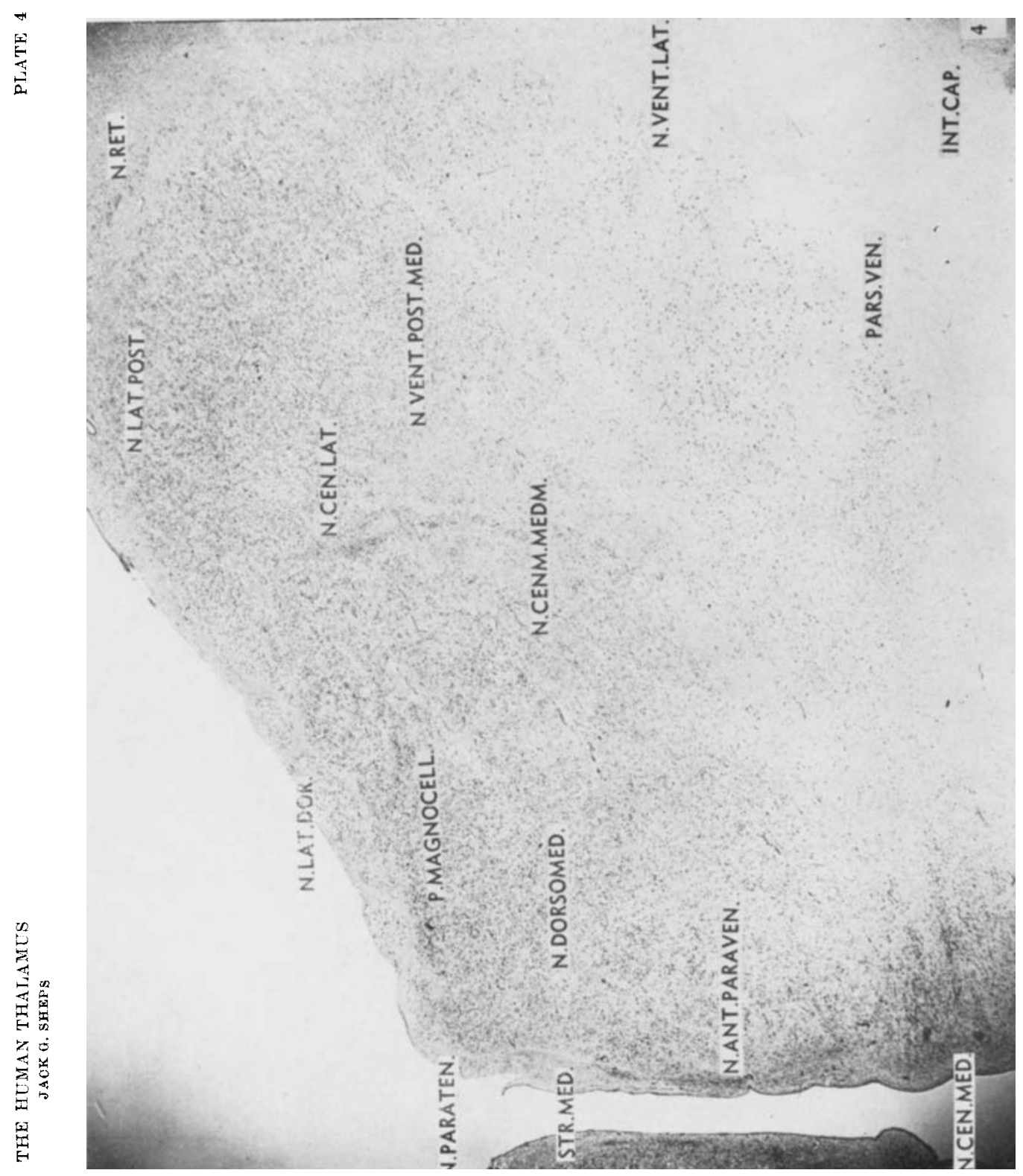




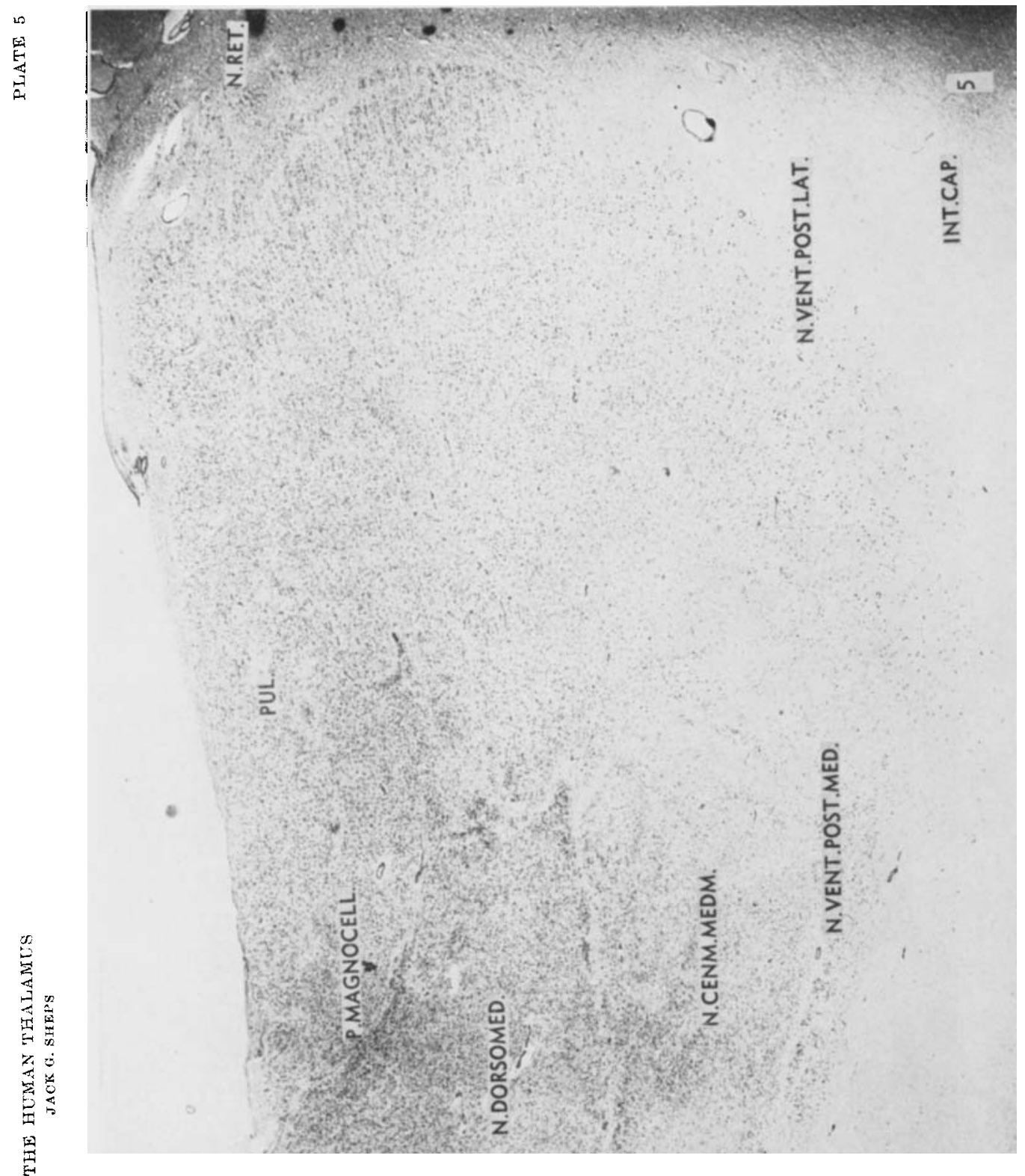




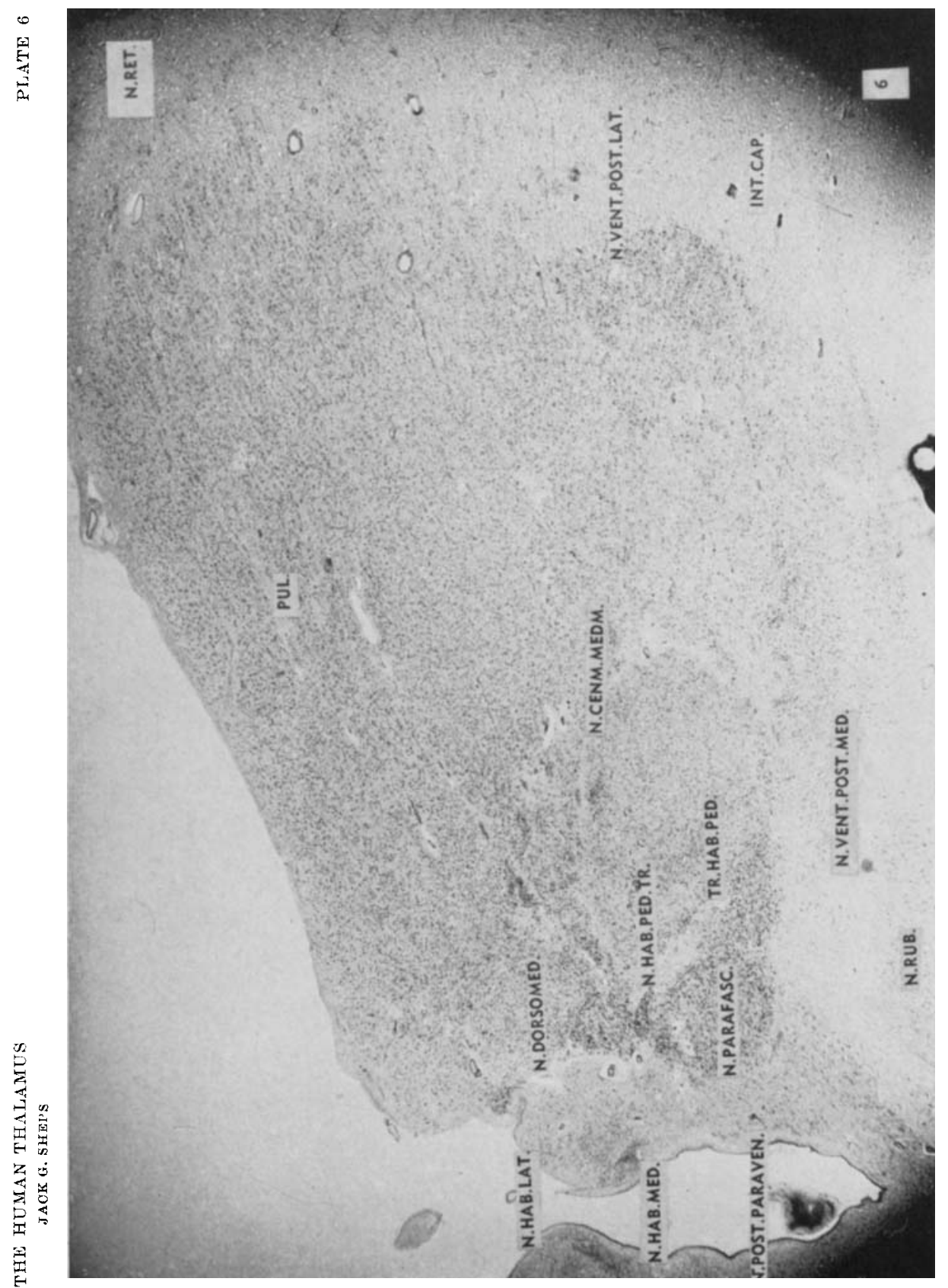




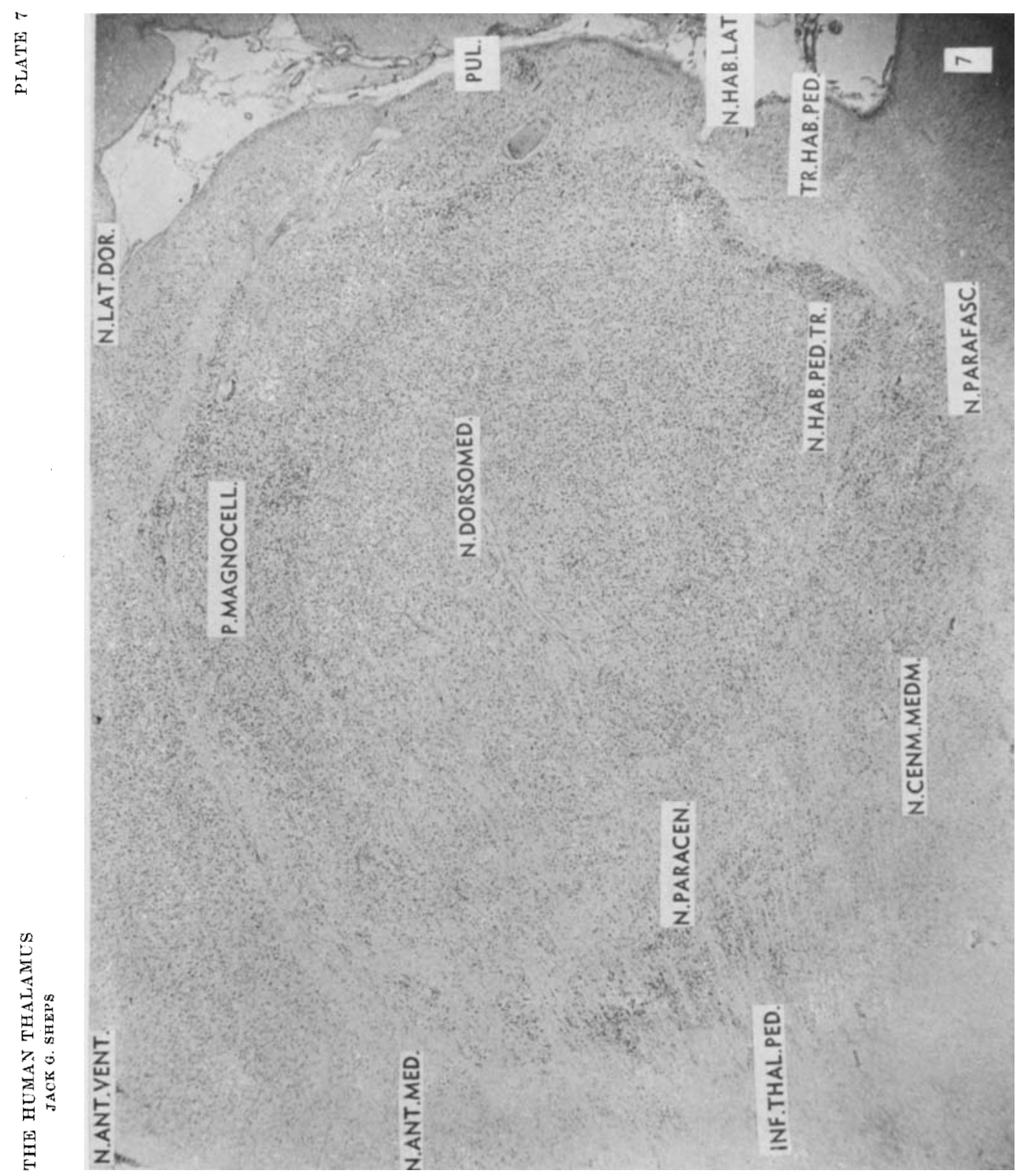




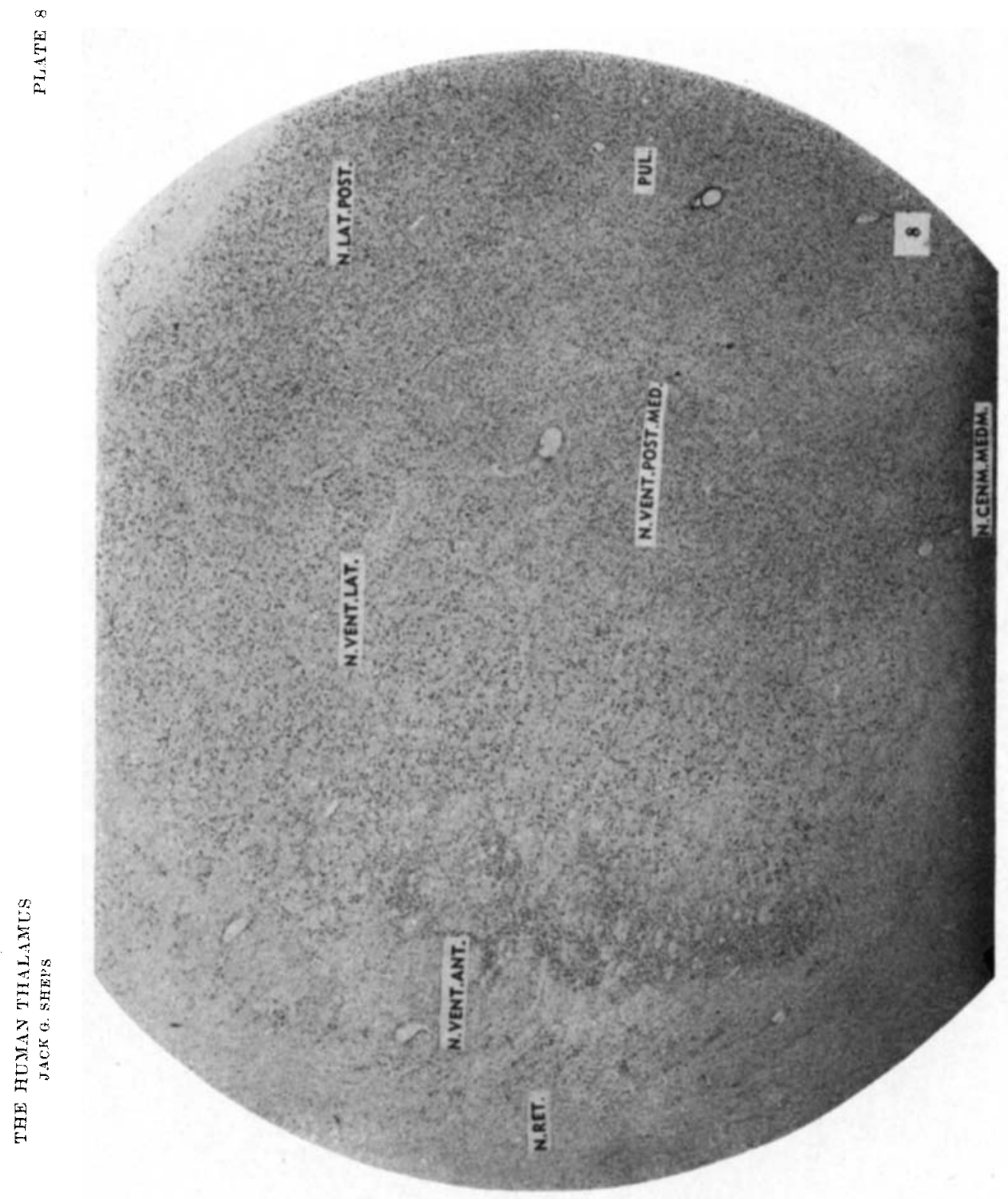




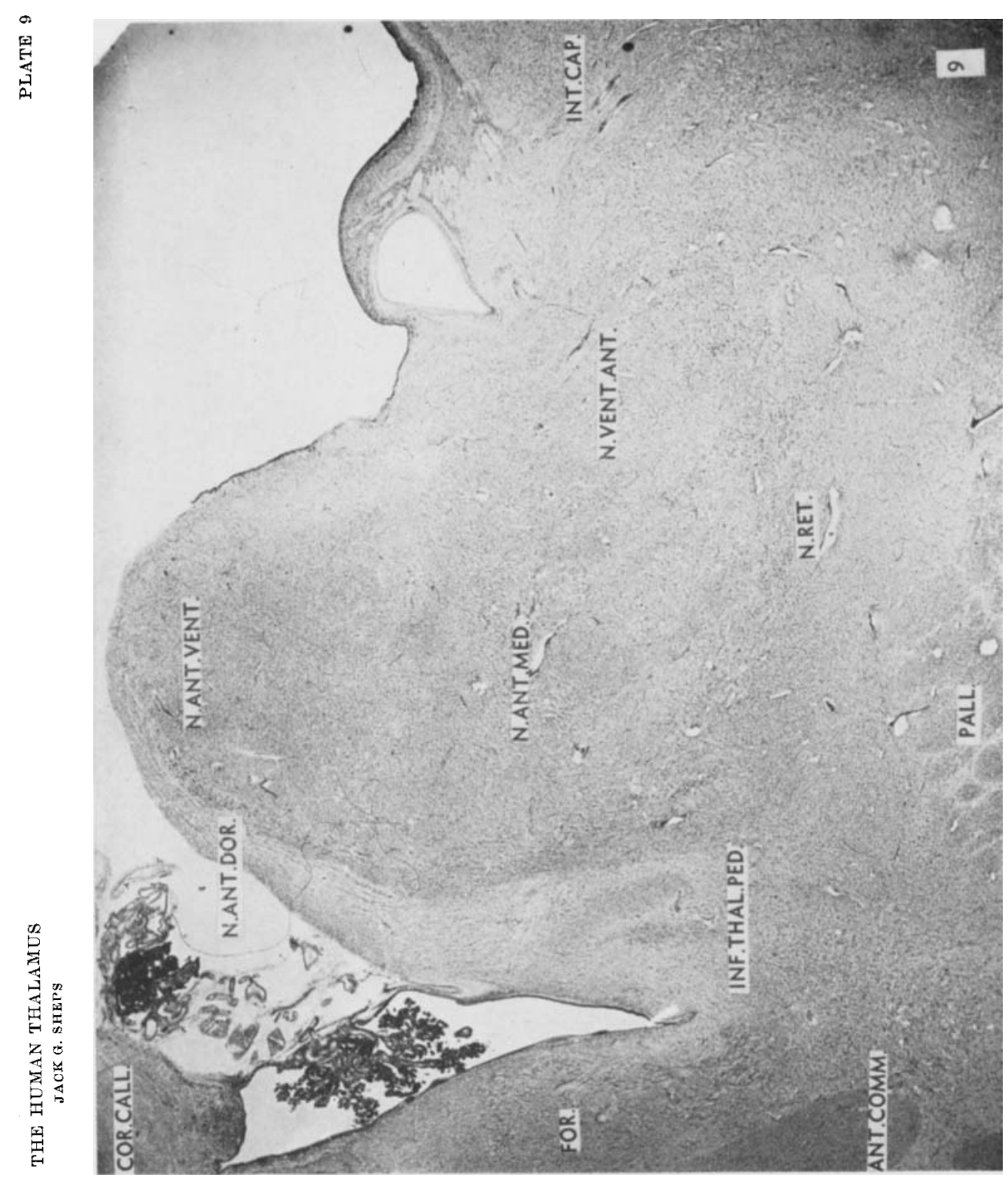


JACK G. SHEPS

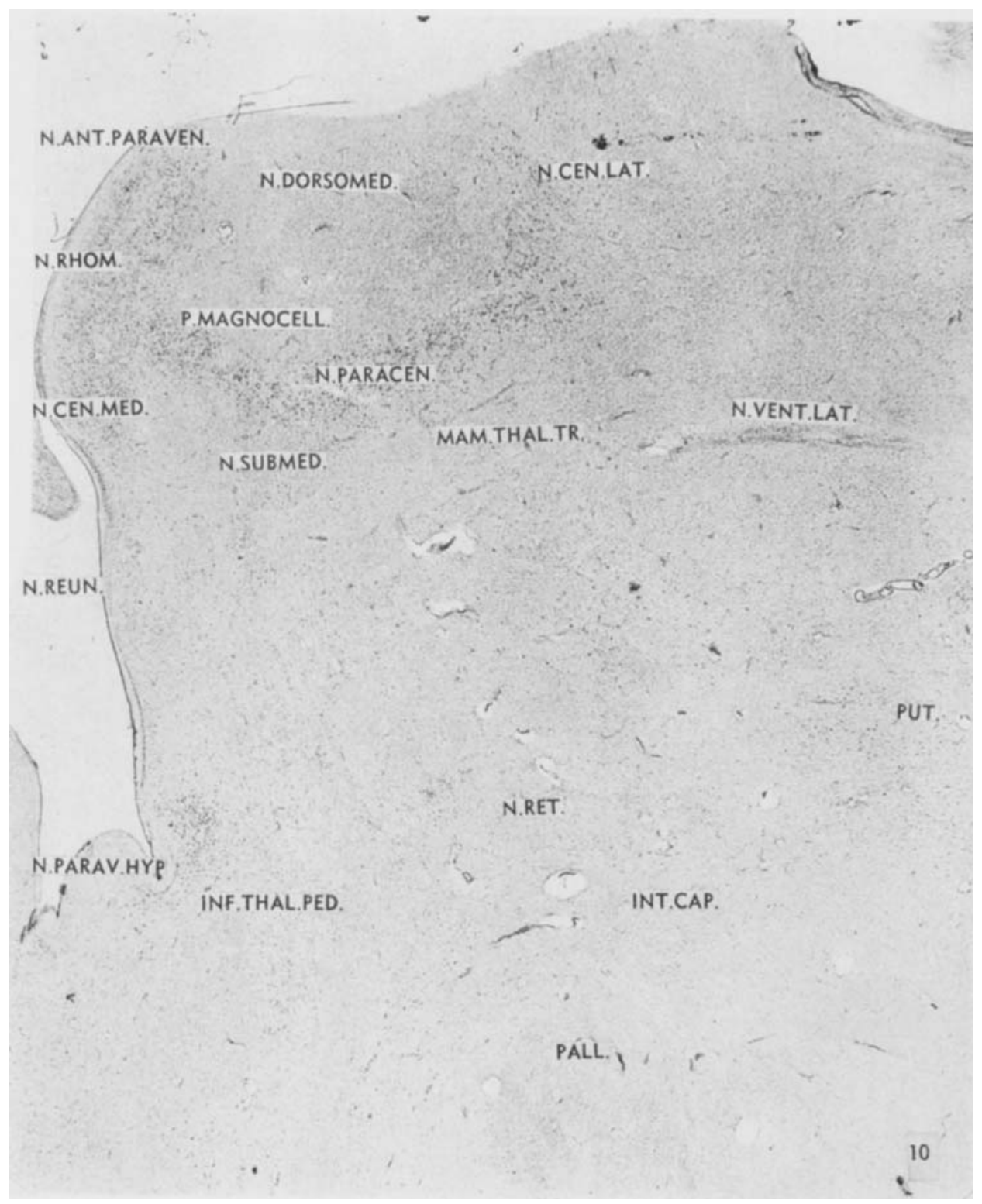




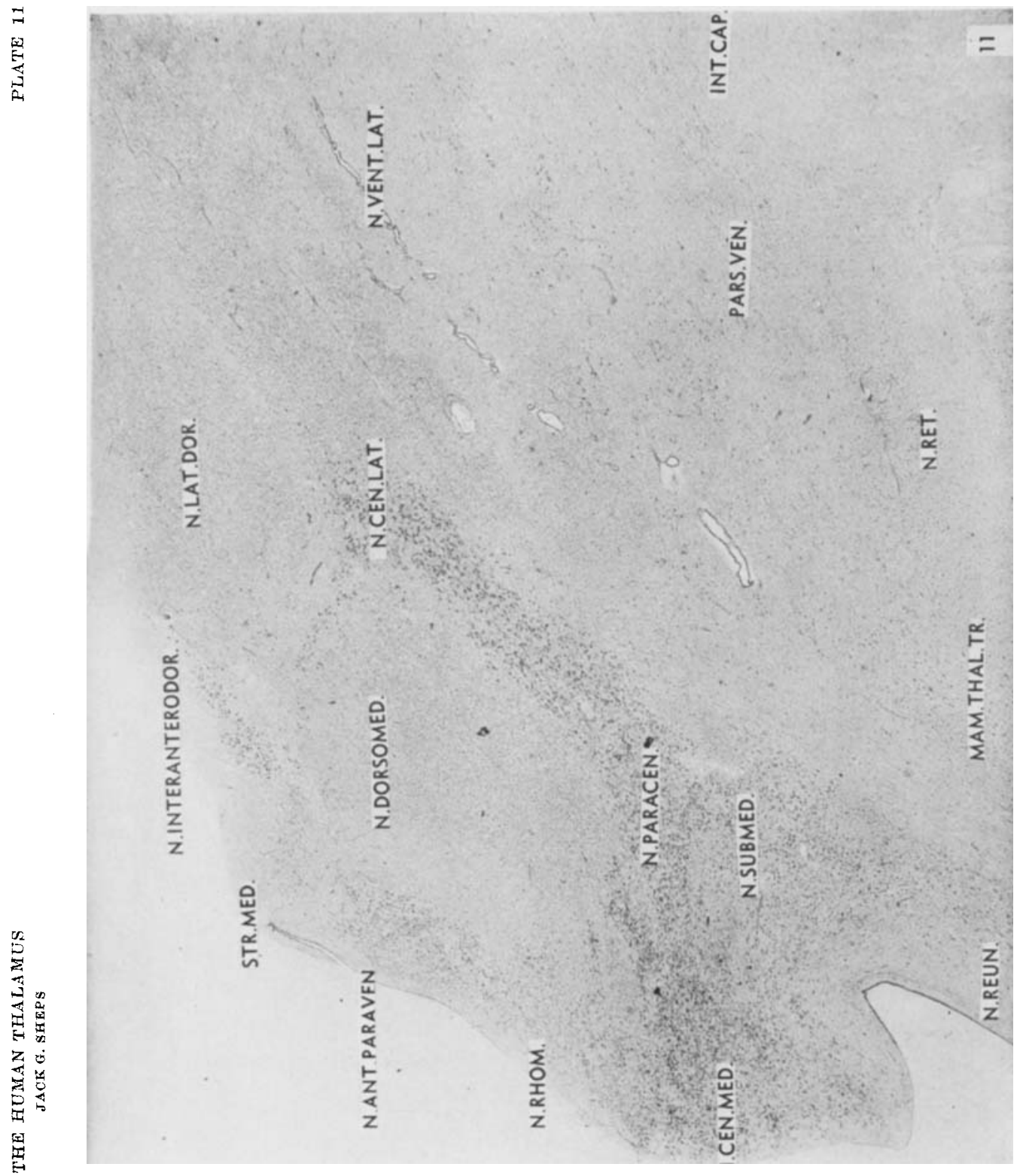




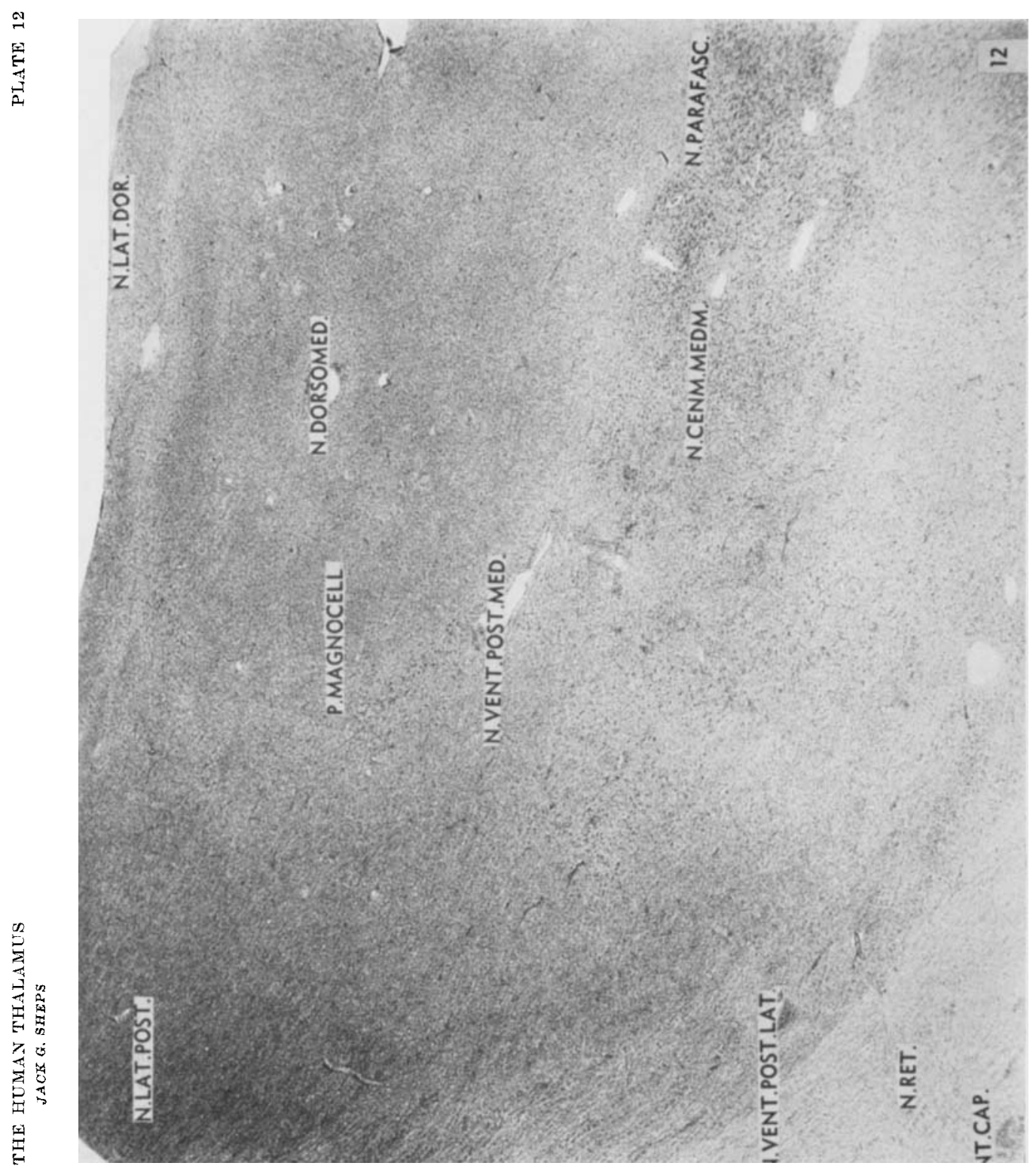


焉

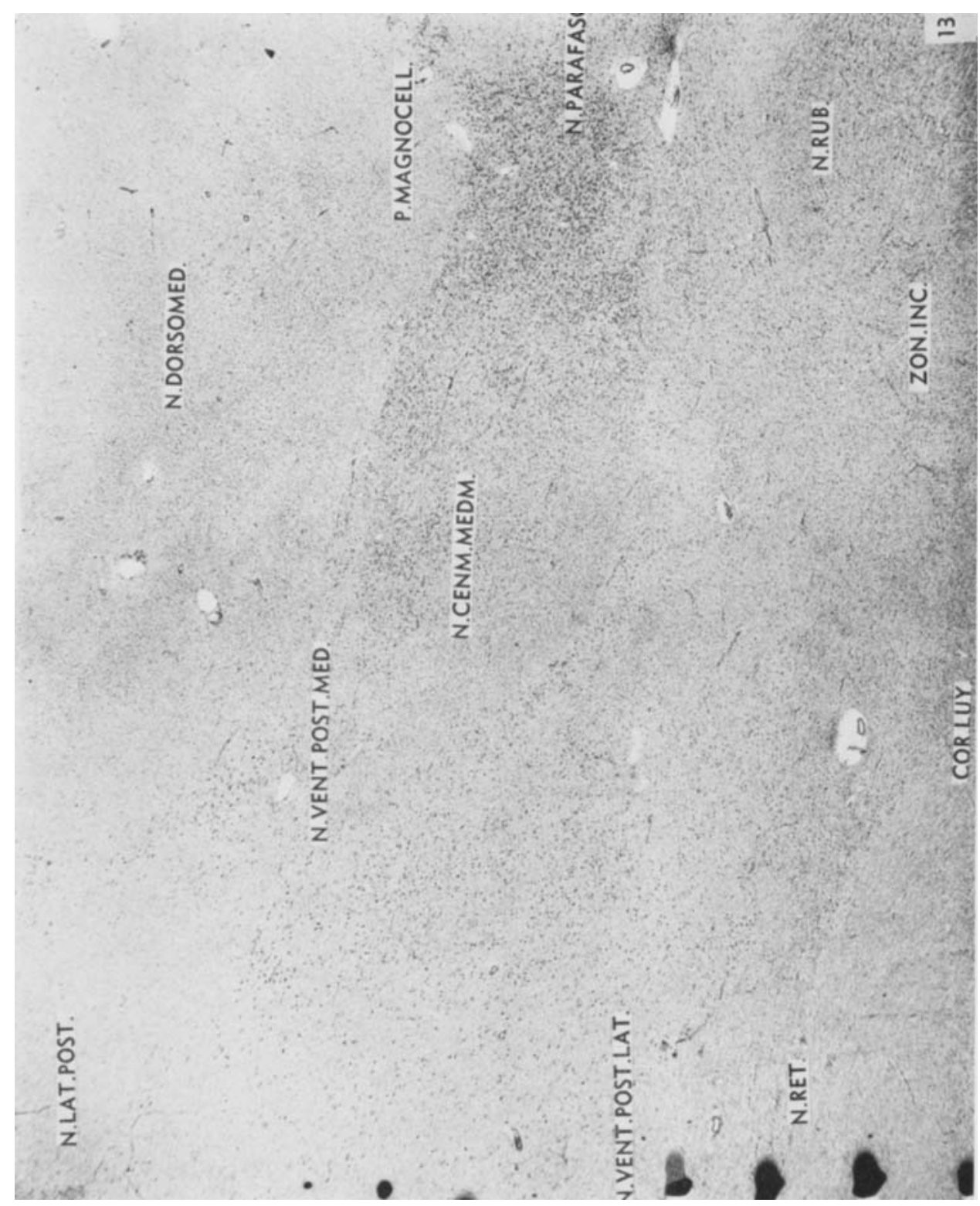




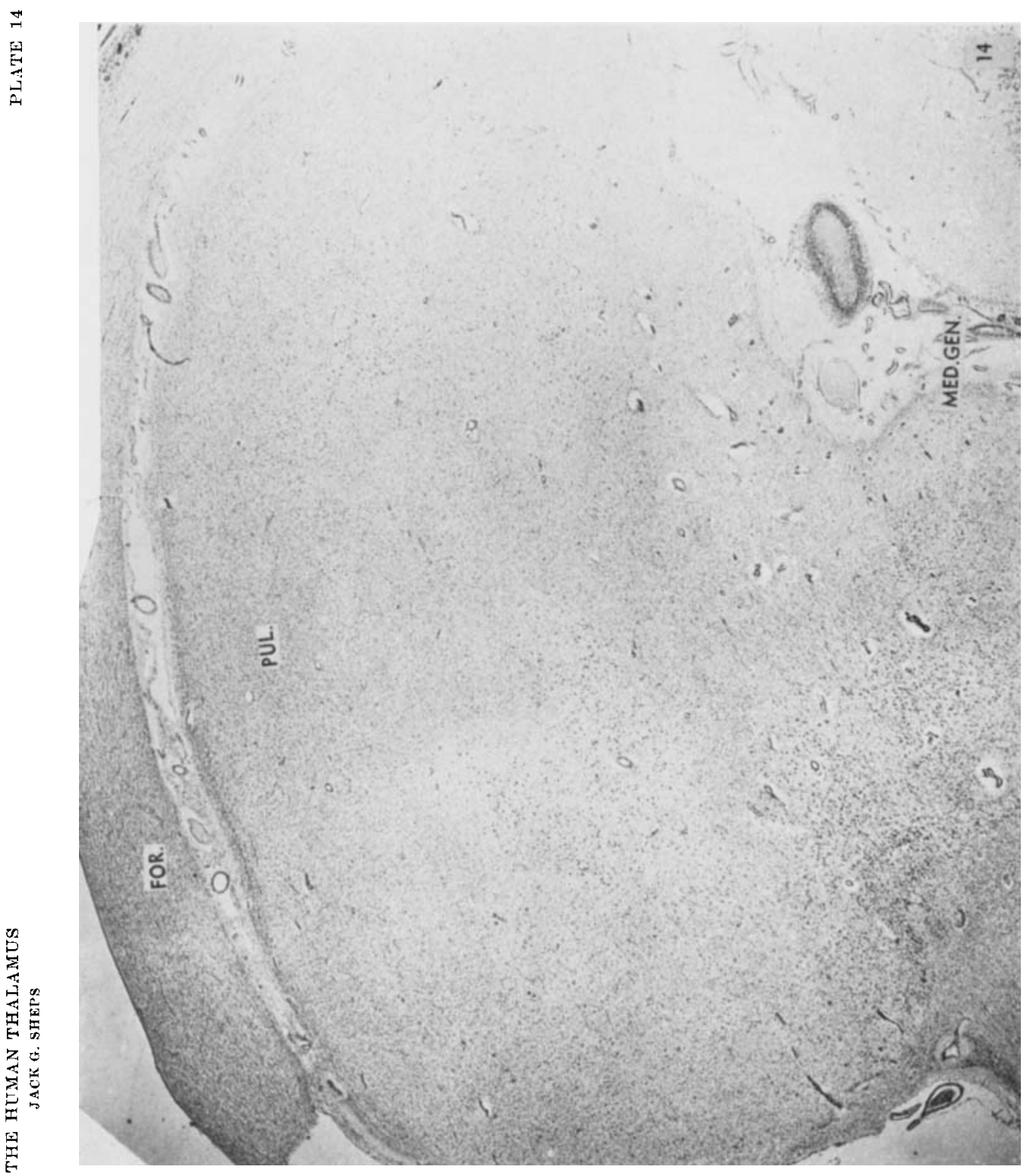



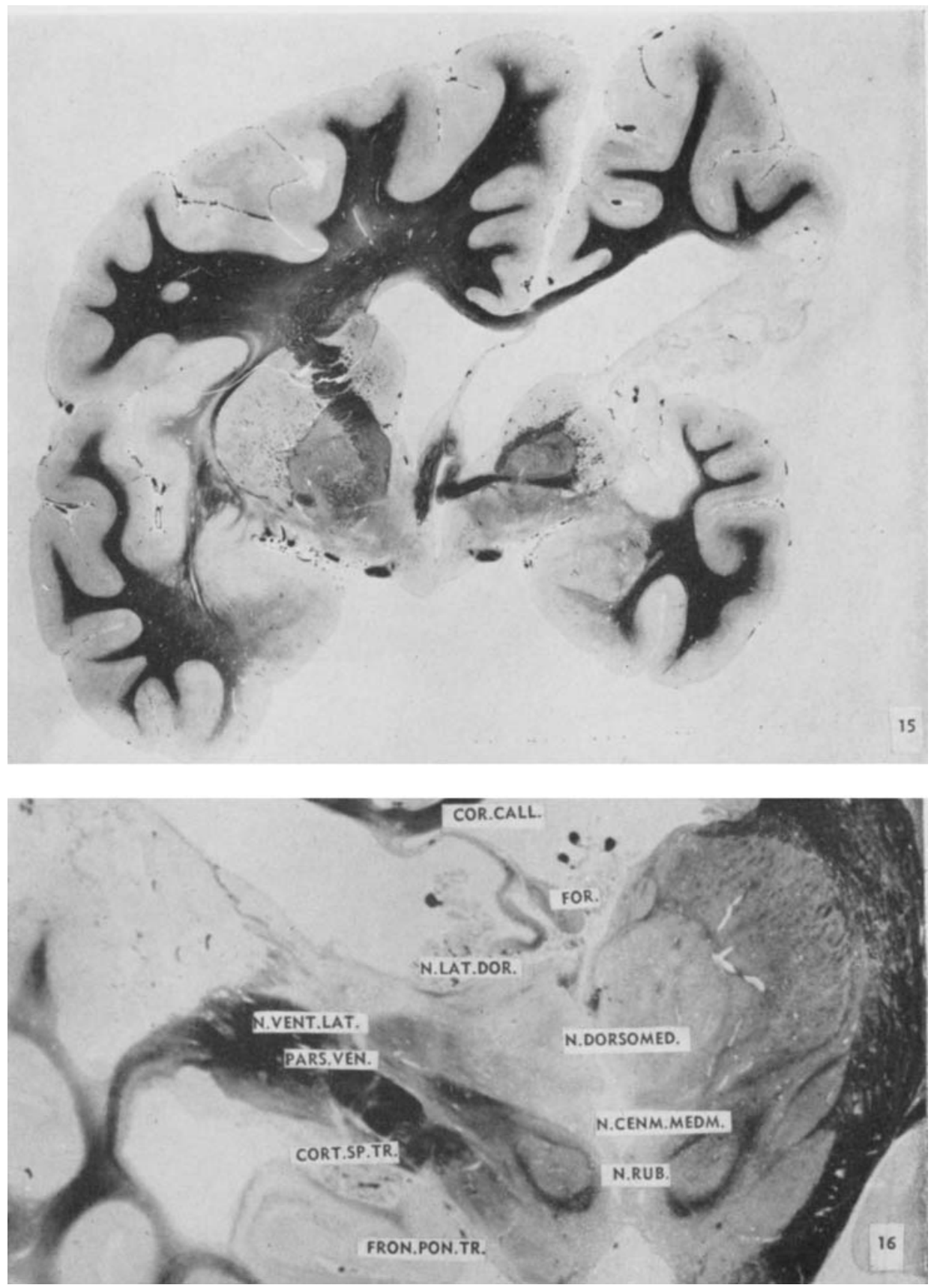


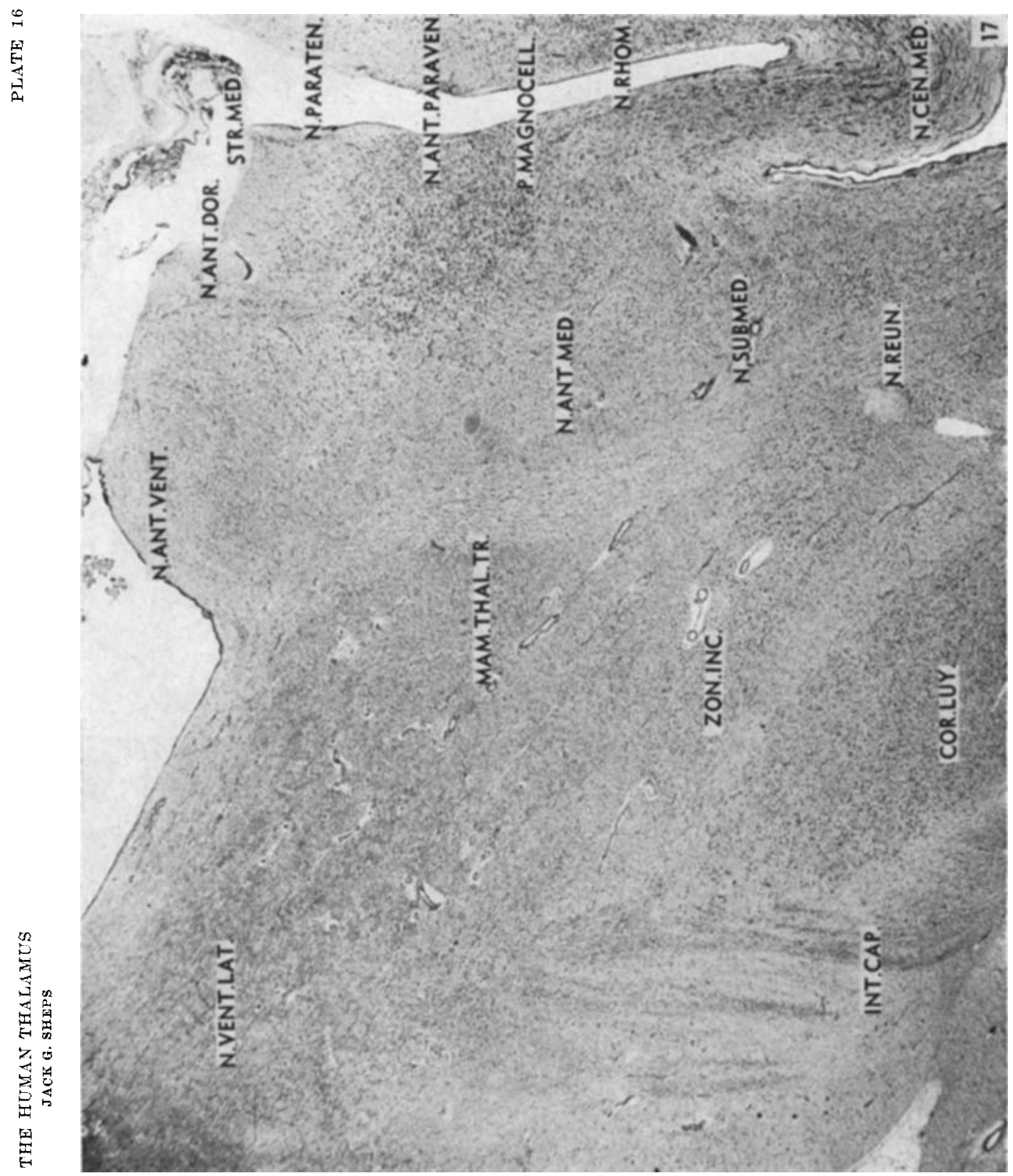




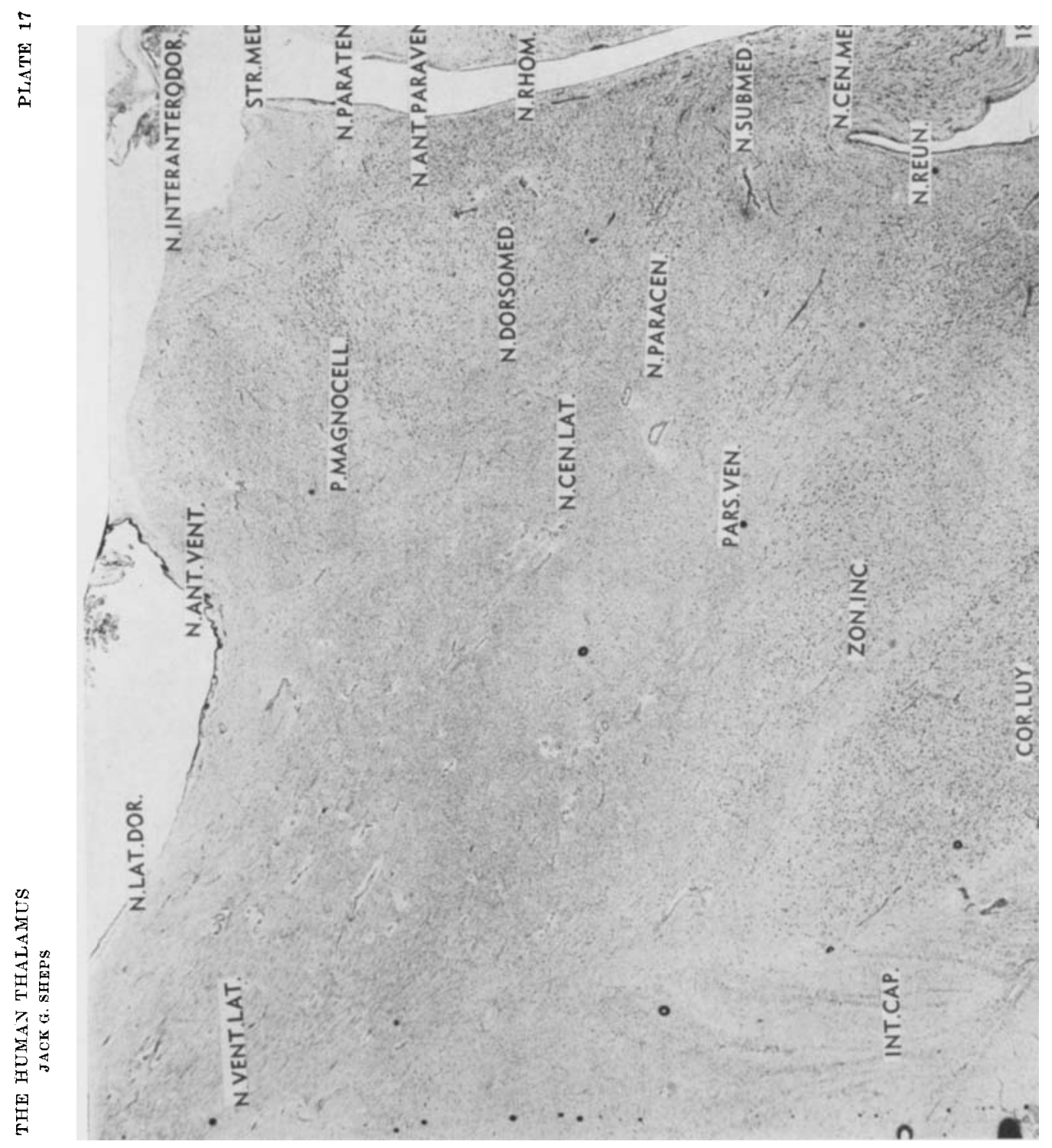



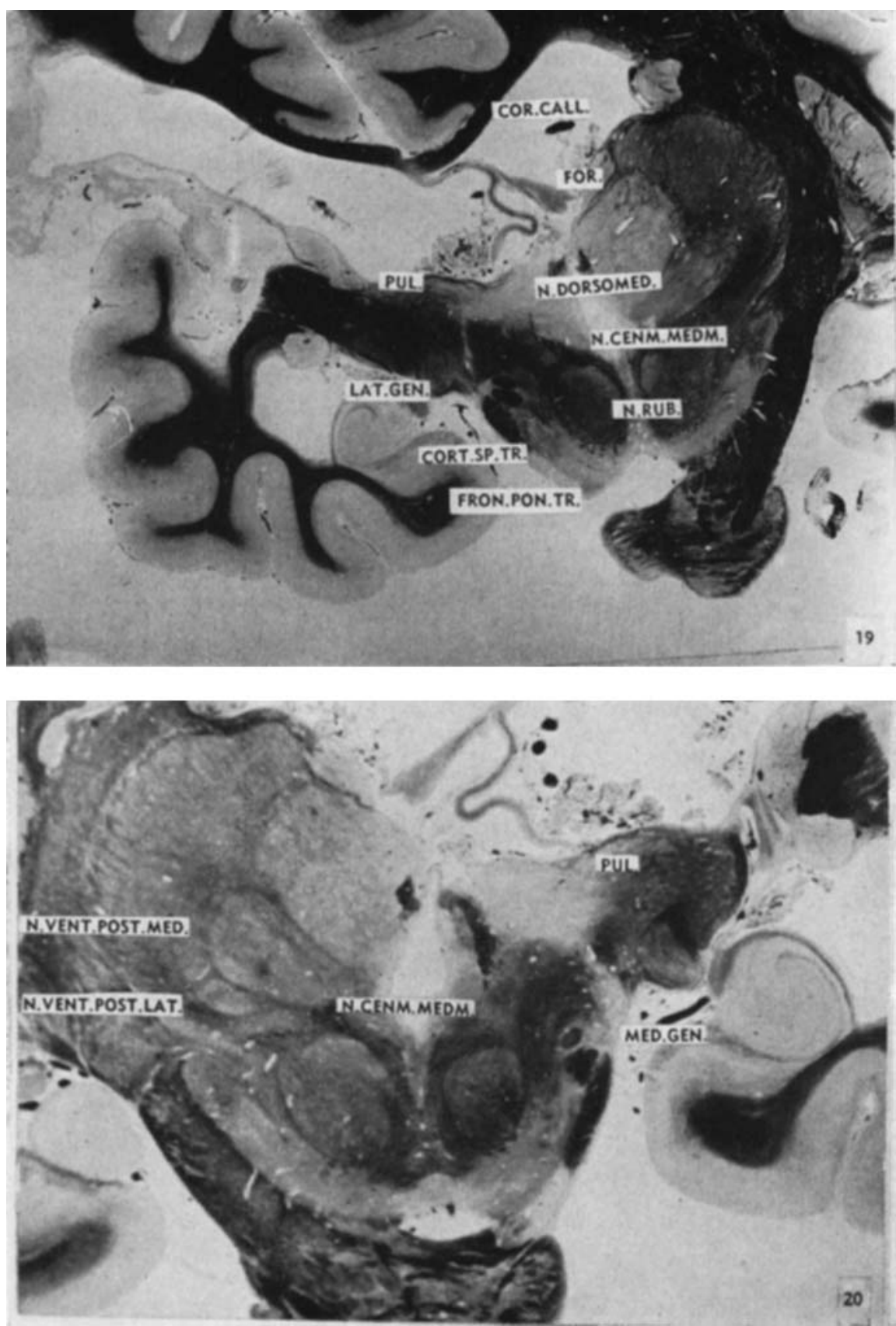
THE HUMAN THALAMUS

PLATE 19 JACK G. SHETS

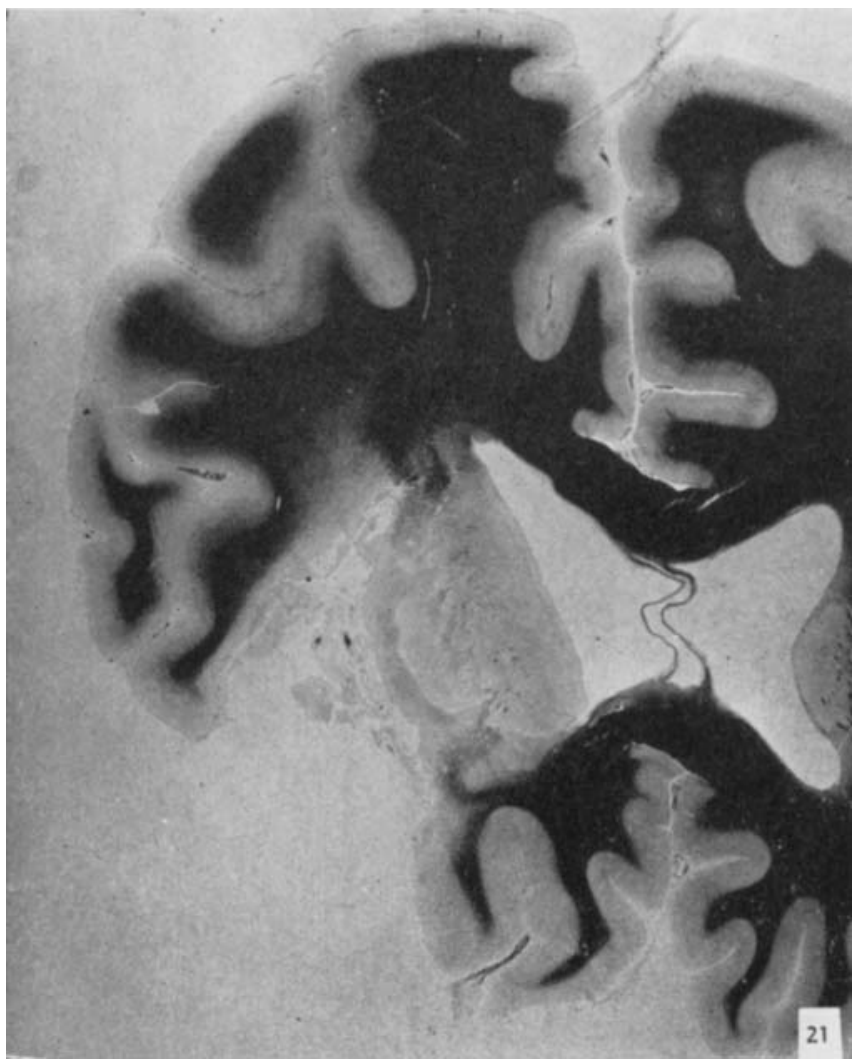



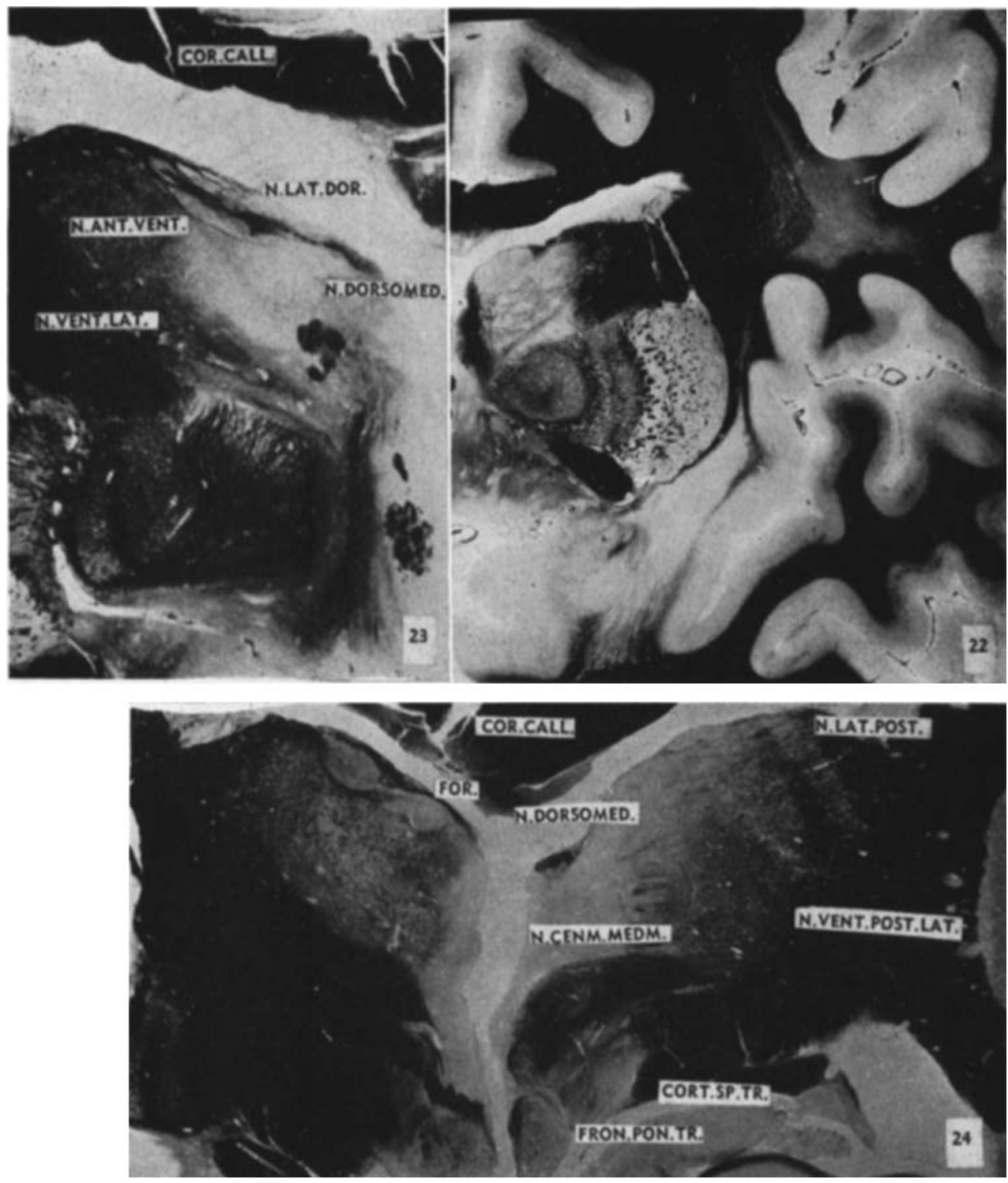